Aus dem Institut für Neuropathologie

(Prof. Dr. med. W. Brück)

im Zentrum Pathologie und Rechtsmedizin

der Medizinischen Fakultät der Universität Göttingen

\title{
Lumbalpunktionsbefunde bei geriatrischen Patienten im Zeitraum 2008-2011
}

\author{
INAUGURAL-DISSERTATION \\ zur Erlangung des Doktorgrades \\ der Medizinischen Fakultät der \\ Georg-August-Universität zu Göttingen
}

vorgelegt von

David Schulz

aus

Bremerhaven

Göttingen 2014 
Die Inhalte der vorliegenden Arbeit wurden publiziert:

Djukic M, Schulz D, Schmidt H, Lange P, Nau R (2013): Cerebrospinal fluid findings in geriatric patients from 2008 to 2011. Z Gerontol Geriatr. 46 (4), 353-357 
Dekan:

1. Berichterstatter:

2. Berichterstatter:

3. Berichterstatter:
Prof. Dr. rer. nat. H.K. Kroemer

Prof. Dr. med. R. Nau

Prof. Dr. med. M. Sommer

Prof. Dr. med. K. Brockmann

Tag der mündlichen Prüfung: $\quad$ 14.01.2015 


\section{Inhaltsverzeichnis}

\section{Abkürzungsverzeichnis}

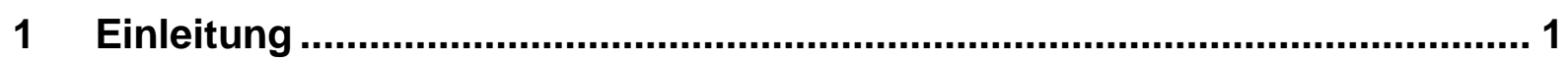

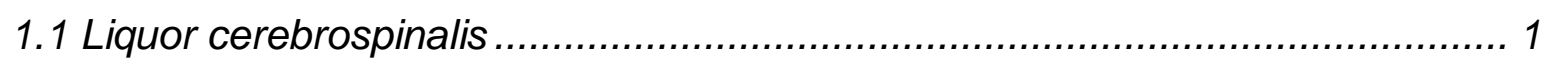

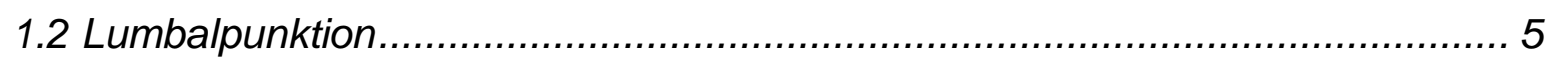

1.3 Einführung in die Liquordiagnostik ........................................................ 11



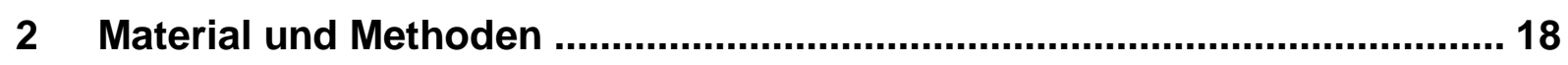

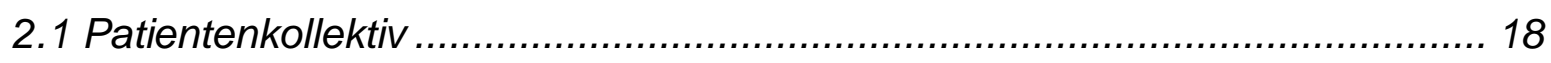

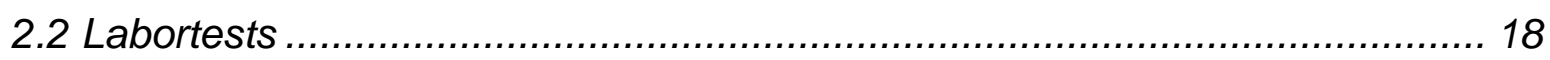

2.2.1 Fuchs-Rosenthal-Zählkammer und Zelldifferenzierung.................... 18

2.2.2 May-Grünwald-Giemsa-Färbung ............................................... 19

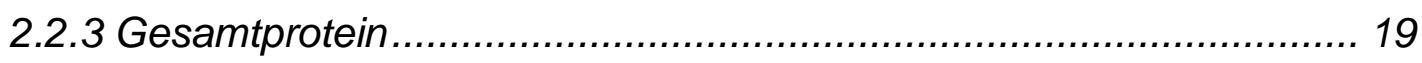

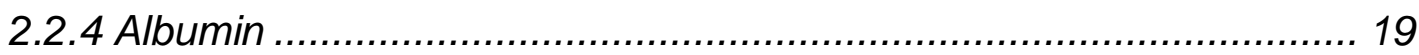

2.2.5 IgG IgA und IgM im Liquor und Serum ....................................... 19

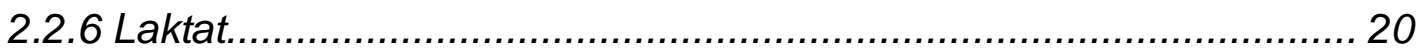



2.2.8 Erregerspezifische Antikörper ..................................................... 20

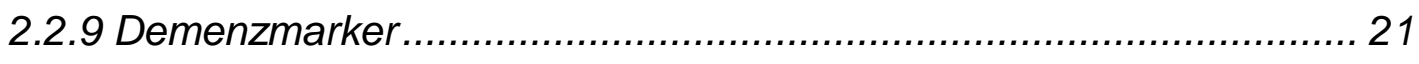

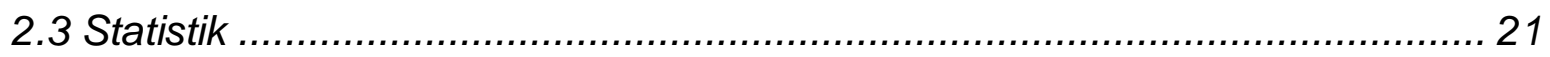

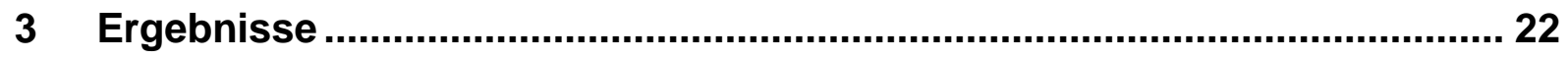

3.1 Erkrankungen und Liquorbefunde ........................................................ 22

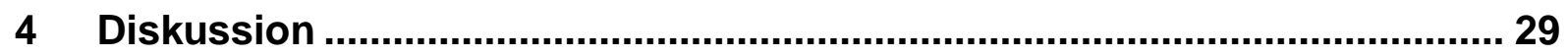

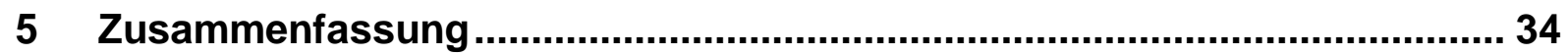

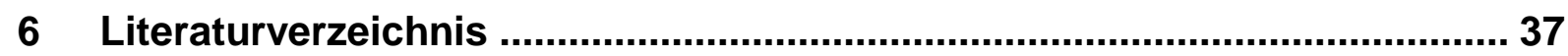




\section{Abkürzungsverzeichnis}

Al

AIDS

BM

BMI

ca.

cCT

CSF

CMRT

E. coli

ED

g

ggf.

HIV

HSV

hVLP

HWK

In-DTPA

$\lg A$

$\lg G$

$\lg M$

KI

LP

LWK

N. meningitidis

NPH

OKB

PPKS

r

$\mathbf{r}_{\mathbf{s}}$

SD
Antikörper-Index

acquired immune deficiency syndrome

bakterielle Meningitis

Body-Mass-Index

circa

kranielle Computertomographie

cerebrospinal fluid

kranielle Magnetresonanztomographie

Escherichia coli

Enzephalomyelitis disseminata

Erdbeschleunigung

gegebenenfalls

Humanes Immundefizienz-Virus

Herpes-Simplex-Virus

high volume lumbar puncture

Halswirbelkörper

Indium-Diethylentriaminpentaessigsäure

Immunglobulin A

Immunglobulin $\mathbf{G}$

Immunglobulin M

Kontraindikation

Lumbalpunktion

Lendenwirbelkörper

Neisseria meningitidis

Normaldruckhydrozephalus

oligoklonale Banden

postpunktioneller Kopfschmerz

Pearson's Korrelationskoeffizient

Spearman's Rangkorrelationskoeffizient

Standardabweichung 
TCA

TM

u.a.

VM

VPS

VZV

ZNS
Trichloressigsäure

transverse Myelitis

unter anderem

virale Meningitis

ventrikulo-peritonealer Shunt

Varizella-Zoster-Virus

zentrales Nervensystem 


\section{$1 \quad$ Einleitung}

\subsection{Liquor cerebrospinalis}

Entdecker des Liquor cerebrospinalis und des Ventrikelsystems war der französische Mediziner, Anatom und Physiologe Francois Magendie. ${ }^{1}$ Als Vorreiter der tierexperiementellen Medizin in Frankreich und der modernen Arzneimitteltherapie findet man seinen Namen noch heute in vielen Bereichen der Medizin. Das BellMagendie-Gesetz ${ }^{2}$, Hertwig-Magendie-Syndrom ${ }^{3}$ und das Foramen Magendii ${ }^{4}$ sind nur einige Hinweise auf seine Leistung in Bezug auf die heutige Medizin (Encyclopaedia Britannica).

Die Rückenmarksflüssigkeit/das Nervenwasser/der Liquor cerebrospinalis, auch kurz nur als Liquor bezeichnet, ist eine dynamische und metabolisch aktive Flüssigkeit, die viele wichtige Aufgaben erfüllt. Der Liquor ist eine klare, farblose und nahezu zellfreie Flüssigkeit, die die Ventrikel und den Subarachnoidalraum, der das Gehirn und Rückenmark umgibt, ausfüllt (Conly und Ronald 1983). Hauptaufgabe des Liquors ist eine Art Schutzschild für das empfindliche Hirnparenchym und das Rückenmark. Er dient als Puffer bei abrupten Kopfbewegungen (z.B. Aufprall des Schädels gegen eine harte Oberfläche) und schützt so das Gehirn vor Kontusionsverletzungen. Ebenso fungiert der Liquor als eine Art Lymphsystem und versorgt das Gehirn mit Nährstoffen und entsorgt anfallende Abbau-/Abfallprodukte. Es wird davon ausgegangen, dass peptidergische und andere Substanzen aktiv als Botenstoffe in den Liquor sezerniert und dort verteilt werden. Hierdurch gelangen sie an verschiedene Stellen des Gehirns und können dort die Aktivität bestimmter Neurone beeinflussen (Veening und Barendregt 2010). Nachgewiesen ist, dass der Liquor in der Embryonalentwicklung eine Schlüsselrolle für die neuronale Entwicklung und Funktion des Gehirns einnimmt (Castells et al. 2012).

\footnotetext{
${ }^{1}$ geboren am 6.10.1783 in Bordeaux, gestorben am 7.10.1855 in Sannois

${ }^{2}$ Unterscheidung der Radix ventralis motoria und der Radix dorsalis sensoria

${ }^{3}$ bestimmter vertikaler Strabismus der Augen

${ }^{4}$ Verbindung zwischen dem vierten Ventrikel und dem Subarachnoidalraum
} 
Normaler Liquor enthält maximal bis zu vier Leukozyten/ $\mu$, wobei zwei Drittel Lymphozyten (Anteil der B-Lymphozyten ca. 1\%, im Vergleich zum Blut mit ca. 5-10\%) und ein Drittel Monozyten sind. Granulozyten und Erythrozyten kommen in normalem Liquor nicht vor. Das Gesamteiweiß des Liquor beträgt etwa 0,2-0,4 g/l und ist damit deutlich niedriger als das Gesamteiweiß des Blutserums mit ca. 60-80 g/l. Das Albumin stellt hierbei die Hauptgruppen dar, sowohl im Serum mit ca. $60 \%$ und im Liquor mit ca. $67 \%$. So lässt sich mit Hilfe des Albumin-Liquor-Serum-Quotienten die BlutLiquor-Schrankenfunktion beurteilen. Der Glukosegehalt des normalen Liquors entspricht ungefähr 50-70\% des Glukosegehalts im Blut und liegt somit zwischen 2,54,2 $\mathrm{mmol} / /$. Der Referenzbereich der Laktatkonzentration ist altersabhängig und liegt bei 1,1-1,8 mmol/l (0-15 Jahre), 1,5-2,1 mmol// (16-50 Jahre) und 1,7-2,6 mmol/l (>51 Jahre) (Kleine et al. 1979, Zettl et al. 2005). Zwischen dem Glukosegehalt und der Laktatkonzentration im Liquor besteht ein inverses Verhältnis (Killian 1925). Sinkt der Glukosegehalt im Liquor z.B. aufgrund einer bakteriellen oder tuberkulösen Meningitis, so steigt im Zuge dessen die Laktatkonzentration an. Schon 1928 konnte bewiesen werden, dass der Liquorlaktatwert einen spezifischeren Paramater zur Beurteilung eines Infektionsverlaufes als der Glukosegehalt im Liquor darstellt (Garcia et al. 1928). Zu unterscheiden sind zwei verschiedene Laktatformen. L- und D-Laktat entstehen als Endprodukte des anaeroben Glukosestoffwechsels vornehmlich in Astrozyten und werden aerob von Neuronen verstoffwechselt (Walz und Mukerji 1988). Im menschlichen Körper liegt fast ausschließlich die L-Form vor. ${ }^{5}$ D-Laktat ist mit einem prozentualen Anteil am Gesamtlaktat von weniger als eins in der Laktatanalytik diagnostisch nicht relevant. Einige Bakterienstämme bilden zwar in vitro stärker D-Laktat als L-Laktat (N. meningitidis ca. 98,1\% D-Laktat, E.coli ca. $97,2 \%$ D-Laktat) - was in der analytischen Differenzierung wegweisend für die Erregerdiagnostik und die darauffolgende spezifische Therapie sein könnte -, aber dies konnte nicht unter In-Vivo-Bedingungen bestätigt werden. Tierexperimentell zeigte sich nur ein Anteil von 4,4\% des D-Laktats am Gesamtlaktat bei einer Infektion mit E.coli und nur 3,9\% D-Laktat bei einer Infektion mit $N$. meningitidis (bei erkrankten Patienten). Dies zeigt deutlich die überwiegende Produktion von L-Laktat (Wellmer et al. 2001). Ein signifikanter Zusammenhang beim Menschen zwischen der Schwere

\footnotetext{
${ }^{5}$ Laktat ist ein Enantiomer; rechtsdrehende L-Form und linksdrehende D-Form in der FischerProjektion
} 
einer Meningitis und der D-Laktat-Produktion konnte nicht nachgewiesen werden (Prange 2004). Eine erhöhte Laktatkonzentration im Liquor bei z.B. schweren bakteriellen Meningitiden ist nur sehr gering dadurch bedingt, dass D-und L-Laktat durch Bakterien selbst produziert werden. Im Vordergrund steht die Fähigkeit bzw. Kapazität der Neuronen, das überwiegend durch die Astrozyten gebildete Laktat zu verstoffwechseln. Durch u.a. eine bakterielle Meningitis kommt es zu einer Aktivitätssteigerung des Hirnparenchyms mit Beteiligung der Neuronen und Astrozyten. Wird im Zuge dieser Aktivitätssteigerung mehr Laktat durch Astrozyten gebildet, als die Neuronen abbauen können, ist also die Kapazität der Neuronen erschöpft, so steigt die Laktatkonzentration an (Walz und Mukerji 1988). Zusätzlich gehen die Neuronen in diesem Prozess mittels anaerober Glykolyse zur Energiegewinnung über, was ebenfalls den Laktatwert erhöht. So ist eine erhöhte Laktatkonzentration im Liquor auf oben genannte Kaskade zurückzuführen und nicht auf die Produktion von D- und L-Laktat durch die Bakterien selber (Prange 2004, Wellmer et al. 2001). Die Bestimmung der Laktatkonzentration im Liquor dient der Unterscheidung zwischen bakteriellen und abakteriellen Meningitiden. Zur Beurteilung wird keine vergleichende Serumlaktatanalyse benötigt, da sich Schwankungen der Blutkonzentration unter normalen Umständen nicht auf die Liquorlaktatkonzentration ausüben (Posner und Plum 1967). Bei akut bakteriellen Meningitiden (außer Neuroborreliose) einschließlich der tuberkulösen Meningitis treten in über $90 \%$ der Fälle Laktatwerte von $\geq 3,5 \mathrm{mmol} / \mathrm{l}$ auf. Bei viral bedingten Meningitiden lassen sich nur in $<1 \%$ erhöhte Laktatwerte über $3,5 \mathrm{mmol} / /$ beobachten. Ebenso gehen vaskuläre Störungen, zerebrale Anfälle und Tumoren (primäre und sekundäre) meistens mit Laktatkonzentrationen von unter $3,5 \mathrm{mmol} / \mathrm{l}$ einher (Petereit et al. 2007, Djukic et al. 2012, Kleine et al. 1979, Luft und Götz 1983).

Gebildet wird der Liquor zu 2/3 durch Ultrafiltration des Blutes in den Plexus chorioidei der vier Hirnkammern/Ventrikel und zu 1/3 durch das Hirngewebe. Die tägliche Produktion liegt bei etwa 0,3 bis $0,4 \mathrm{ml}$ pro Minute, was etwa einer Gesamtmenge von $500 \mathrm{ml}$ pro Tag entspricht. Da das durchschnittliche Liquorvolumen des Erwachsenen nur ca. $150 \mathrm{ml}$ beträgt, unterliegt der Liquor einem ständigen Kreislauf von Produktion und Resorption (Reiber 2006a). Die Ventrikel fassen insgesamt ein Volumen von ca. $25 \mathrm{ml}$. Die restlichen $125 \mathrm{ml}$ entfallen auf den Subarachnoidalraum, wobei bis zu $30 \mathrm{ml}$ im spinalen Anteil des Subarachnoidalraums verteilt sein können (Sakka et al. 2011). Gebildet in den vier Ventrikeln fließt der Liquor durch das 
Foramen Magendii und die beiden Foramina Luschkae in die basalen Zisternen und verteilt sich dort in den kortikalen und lumbalen Teil des Subarachnoidalraums (Reiber 2006a). Die Resorption des Liquors findet in den Arachnoidalzotten bzw. in den Pacchioni-Granulationen statt, die sich überwiegend an den kleineren Venen befinden. Diese sind kraniale (Sinus sagittalis), gefäßfreie Ausstülpungen der Arachnoidea mater. Des Weiteren erfolgt eine Resorption entlang der Perineuralscheiden der Hirn- und Spinalnerven. Ohne Filtration (bulk flow) wird der Liquor dort in das venöse System drainiert (Davson und Segal 1996). Mit zunehmendem Alter nimmt die Produktion und somit die Fließgeschwindigkeit des Liquor ab. Etwa vier Monate nach der Geburt sind die Arachnoidalzotten ausgereift und somit wird eine maximale Geschwindigkeit erreicht. Mit steigendem Alter nimmt die Fließgeschwindigkeit durch verminderte Produktion in den Ventrikeln ab und erreicht zum Ende hin nur ca. $0,1 \mathrm{ml} / \mathrm{min}$ (May et al. 1990). Die Fließgeschwindigkeit des Liquors ist abhängig von verschiedenen Größen und wird unter anderem durch Atmung, Lage des Körpers und Herzfunktion beeinflusst. Anatomische Fehl- oder Missbildungen, Tumoren, Verletzungen, ZNS-Infektionen oder degenerative Veränderungen des Gehirns können zu einer Zirkulationsstörung oder zu Abflussstörungen in diesem Kreislauf führen und somit verschiedene Krankheitsbilder hervorrufen. Zu nennen seien hier der Hydrozephalus als Überbegriff für die verschiedenen Formen (Hydrocephalus internus, occlusivus oder malresorptivus, Hydrocephalus externus, Hydrocephalus communicans, Normaldruckhydrozephalus) oder das Krankheitsbild des Pseudotumor cerebri. Die meisten Zirkulationsstörungen/Abflussstörungen gehen mit einer Erhöhung des intrakraniellen Druckes einher. Ebenso folgt auf eine Volumenzunahme des Hirnparenchyms und/oder des intrakraniellen Blutvolumens ein Anstieg des Hirndrucks, sobald eine Kompensation durch den Subarachnoidalraum nicht mehr gewährleistet ist. Der physiologische Normwert des Hirndruckes liegt bei gesunden jungen Erwachsenen zwischen 5 und $15 \mathrm{mmHg}(5-20 \mathrm{~cm}$ Wassersäule), bei Kindern zwischen 0 und $10 \mathrm{mmHg}$. Gemessen wird im Liegen, wobei das Foramen Monroi als Nullpunkt festgelegt wurde. Druckspitzen von bis zu $50 \mathrm{mmHg}$ durch abdominellen Druckaufbau, z.B. beim Husten, stellen kurzfristig kein Problem dar und führen zu keiner neurologischen Schädigung (Oschmann et al. 2005). Ein rascher Anstieg des intrakraniellen Druckes (durch z.B. intrakranielle Blutungen, Liquorabflussstörungen) über $20 \mathrm{mmHg}$ führt schnell und plötzlich zu klinischen Hirndruckzeichen wie schwallartiges Erbrechen, Übelkeit, Kopfschmerzen, Inappetenz und Vigilanzstörungen. Eine intensivme- 
dizinische Überwachung und Behandlung ist nun indiziert. Ein chronischer und langsam verlaufender Hirndruckanstieg bewirkt u.a. eine Minderperfusion des Hirnparenchyms und damit eine Anreicherung von Stoffwechselprodukten mit einer darauffolgenden Vasodilatation. Durch u.a. Autoregulation der Hirngefäße und Hypokapnie wird zunächst eine Kompensation erreicht. Persistiert jedoch die Minderperfusion des Hirnparenchyms, schaltet sich die Autoregulation der Hirngefäße aus und es kommt zu einem Anstieg des intrazerebralen Blutvolumens durch die Cushing-Reaktion (pathophysiologische Reaktion einhergehend mit arterieller Hypertension, Bradykardie und irregulärer Atmung, um die zerebrale Perfusion und Oxygenation aufrecht zu erhalten). Die Folge ist ein Hirnödem mit konsekutivem Hirndruckanstieg, Kompression der inneren und äußeren Liquorräume bis hin zum Einklemmungssyndrom (Masuhr und Neumann 2007). Wird dieser Circulus vitiosus nicht durchbrochen, sistiert am Ende die zerebrale Durchblutung. Auch hier ist eine schnelle intensivmedizinische Behandlung vonnöten, um den drohenden Exitus letalis zu verhindern.

\subsection{Lumbalpunktion}

Corning führte 1885 die erste Lumbalpunktion durch. Quincke schrieb über die Technik der Lumbalpunktion und die Untersuchung des Liquors 1891. Seit dieser Zeit ist die Lumbalpunktion zu einem wichtigen zentralen Mittel in der Beurteilung von Infektionen des Zentralen Nervensystems (ZNS), anderer ZNS-Entzündungen, Subarachnoidalblutungen und neurodegenerativer Erkrankungen geworden (o.Verf. 1993). Weniger häufig wird die Lumbalpunktion auch als Teil der Therapie für Patienten mit Hydrocephalus aresorptivus oder Normaldruckhydrozephalus gebraucht. Ferner steht die Applikation von Medikamenten, z.B. Chemotherapeutika oder Antibiotika, als therapeutische Möglichkeit zur Wahl (Thiel und Gleissner 2006). Neben der Lumbalpunktion als Standardverfahren bestehen noch weitere Zugangswege zur Liquorgewinnung wie die Subokzipitalpunktion oder die Ventrikelpunktion (Storch-Hagenlocher 2006a). Die Ventrikelpunktion ist nur durch einen operativneurochirurgischen Eingriff durchführbar und kommt in der heutigen Medizin z.B. bei einem Verschlusshydrozephalus auf Grund einer basalen Verklebung der Meningen (z.B. bei der eitrigen Meningitis) zum Einsatz. Dieses Verfahren dient in erster Linie als Therapie und nicht zur Diagnostik, wobei natürlich der gewonnene Liquor 
untersucht werden kann und sollte. Die Durchführung einer zervikalen bzw. subokzipitalen Punktion unterliegt heute einer sehr strengen Indikation. Die Nähe der Medulla oblongata zur Punktionsstelle (zervikolateral zwischen HWK 1 und 2 bzW. am Unterrand des Okziput) und ein hohes Risiko von Gefäßverletzungen begrenzen die Indikationsstellung der zervikalen Punktion. Ist aufgrund von tumorösen Veränderungen, lokalen Entzündungen oder schwerer Osteochondrose eine Lumbalpunktion nicht möglich, wird auf dieses Verfahren zurückgegriffen (StorchHagenlocher 2006a).

Am Anfang der Lumbalpunktion steht, wie bei allen invasiven Eingriffen, die Aufklärung und das Einverständnis des Patienten. Mindesten 24 Stunden vor dem Eingriff muss dieses durch den Patienten schriftlich bestätigt werden (Ausnahme in Notfallsituationen). Nach Ausschluss von Kontraindikationen (KI) (Tabelle 1) und einer strengen Indikationsstellung (Tabelle 2) wird der Patient für die Punktion vorbereitet.

\section{Tabelle 1: Kontraindikationen für die Durchführung einer Lumbalpunktion}

\section{Kontraindikationen}

- Kardiorespiratorische Erkrankungen, die die notwendige Lagerung nicht erlauben

- Klinisch manifester erhöhter intrakranieller Druck (Gefahr der zerebralen Einklemmung)

- Lokale Entzündungen (Gefahr der Keimverschleppung)

- Gerinnungsstörungen*: Thrombozytenzahl < 50000/Einheit relative KI Thrombozytenzahl < 20000/Einheit absolute KI

( ${ }^{*}$ ein Thrombozytenaggregationshemmer oder niedermolekulare Heparine in lowdose stellen keine $\mathrm{KI}$ dar)

(Diener und Weimer 2012) 
Tabelle 2: Indikationen (diagnostische und therapeutische) für die Durchführung einer Lumbalpunktion

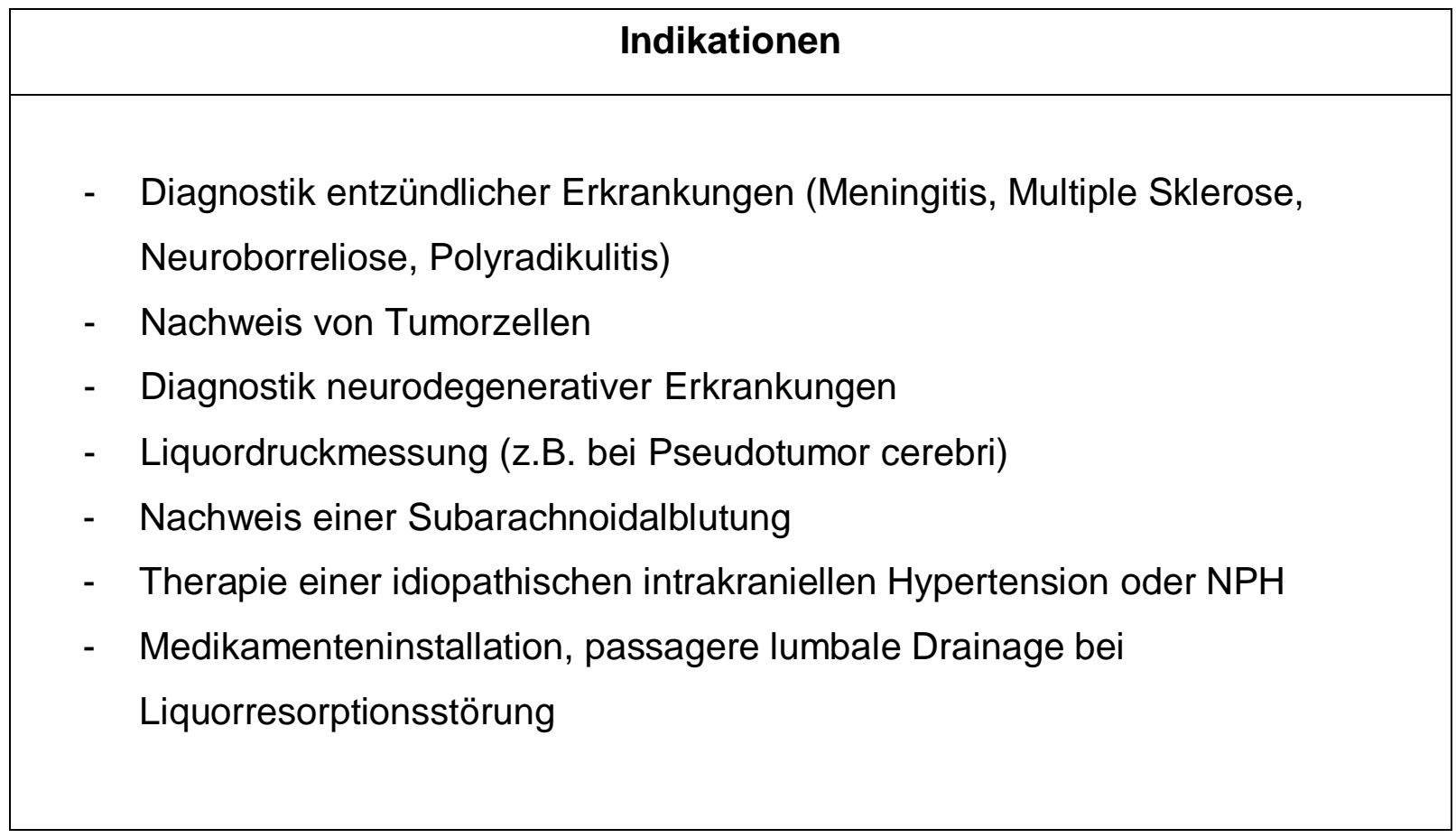

(Diener und Weimer 2012)

Bei Verdacht auf eine intrakranielle Druckerhöhung ist die Durchführung einer kraniellen Computer- (cCT) oder einer kraniellen Magnetresonanztomographie (cMRT) obligat. Das Spiegeln des Augenhintergrundes reicht zum Ausschluss eines erhöhten Hirndruckes nicht aus (Gröschel et al. 2008).

Der Patient wird sitzend oder liegend gelagert, wobei die Punktion im Sitzen als weniger schwierig gilt. „Wesentlich ist eine entspannte Lage für den Patienten mit möglichst maximaler Ventralflexion und Dehnung der LWS („Katzenbuckel“) sowie flektierten Beinen." (Storch-Hagenlocher 2006a, S. 32) [siehe Abbildungen $1+2$ ] 
Abbildung 1: Lagerung eines Patienten im Sitzen zur Durchführung einer Lumbalpunktion

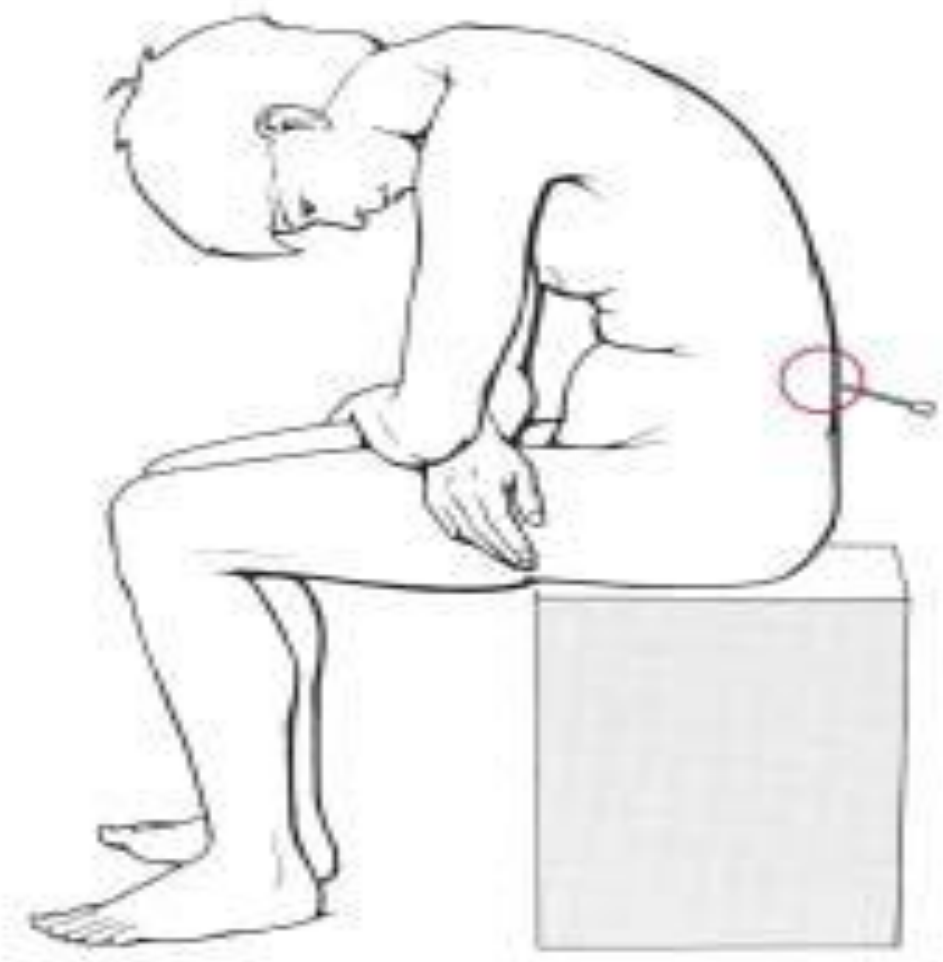

(aus Masuhr und Neumann 2007, S. 124)

Abbildung 2: Lagerung eines Patienten im Liegen zur Durchführung einer Lumbalpunktion



(aus Masuhr und Neumann 2007, S. 124) 
Die möglichen Punktionsstellen liegen in den Zwischenräumen LWK 3/4, LWK 4/5 oder LWK 5/S1. Zur besseren Orientierung nutzt man die anatomische Lage der beiden Cristae iliacae, auf deren gedachter Verbindungslinie der Processus spinosus des 4. LWK liegt. Von dort aus lassen sich nun die möglichen Punktionsstellen, die jeweils ca. $1 \mathrm{~cm}$ unterhalb des Processus spinosus liegen, finden. Nach obligatorischer Desinfektion und Abdeckung der bestimmten Punktionsstelle kann bei verspannten oder ängstlichen Patienten zusätzlich zu einer Lokalanästhesie auch ein Benzodiazepin verabreicht werden (Gröschel et al. 2008).

Als Punktionsnadeln stehen zwei verschiedene Modellarten zur Verfügung. Die „traumatische“ Quincke-Nadel besitzt eine scharf-geschliffene Spitze mit relativ größerem Innendurchmesser im Vergleich zur „atraumatischen“ Sprotte-Nadel mit einer konisch-runden Spitze (Abbildung 3). In der Routinediagnostik wird vermehrt die Sprotte-Nadel (siehe unten) bevorzugt (Storch-Hagenlocher 2006a).

\section{Abbildung 3: Punktionsnadeln}

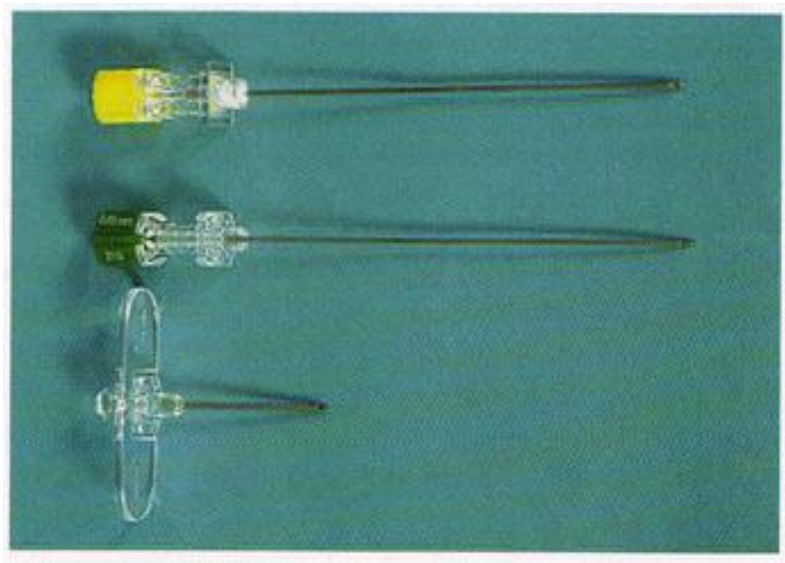

Lumbalpunktionsnadeln: Mitte: Sprotte-Nadel mit Führungstrokar. Oben: Quincke-Nadel

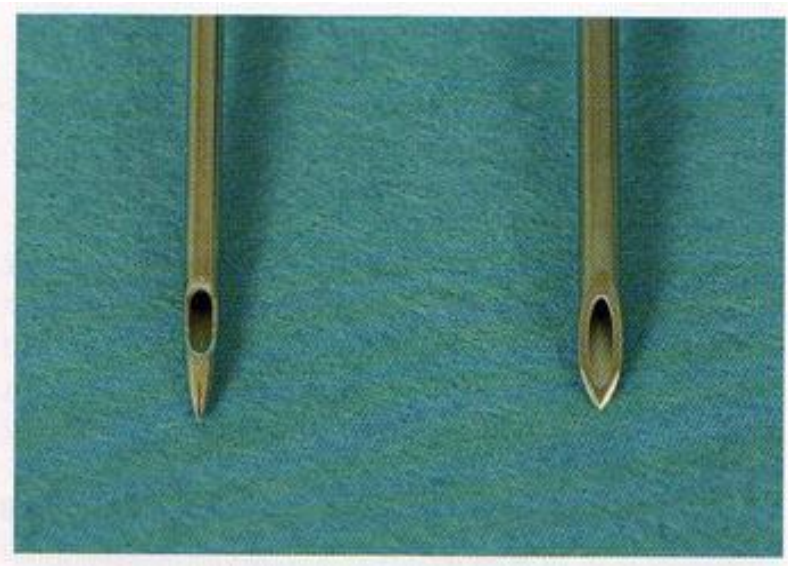

Vergleich der scharf-geschliffenen Spitze der Quincke-Nadel (rechts) mit der konischrunden Spitze und seitlichen Öffnung der Sprotte-Nadel (links)

(aus Storch-Hagenlocher 2006a, S. 31)

Die Nadel wird in leicht kranialer Richtung (ca. $20 \mathrm{Grad}$ ) unterhalb des Processus spinosus eingeführt. Die Eindringtiefe variiert je nach körperlichem Zustand des Patienten, liegt aber im Durchschnitt zwischen 3,5 und 4,5 cm. Das Ligamentum flavum wird als Widerstand in ungefähr $3 \mathrm{~cm}$ Tiefe bemerkbar. Nach Durchstechen 
des Ligamentum flavum und der Dura mater liegt die Spitze der Nadel nun im Liquorraum und es kann mit der Liquorentnahme begonnen werden (StorchHagenlocher 2006a).

Die weitaus häufigste Komplikation in Verbindung mit einer Lumbalpunktion ist der postpunktionelle Kopfschmerz (PPKS), der bei ca. $40 \%$ der Patienten auftritt $(<1$ bis $70 \%$ ) (Strupp et al. 2001). In einer Studie (Carson und Serpell 1996) konnte gezeigt werden, dass das Auftreten des postpunktionellen Kopfschmerzes sich entscheidend von der Art der Punktionsnadel beeinflussen lässt. In nur 12,2\% der Lumbalpunktionen mit der Sprotte-Nadel, im Gegensatz zu 24,4\% mit der Quincke-Nadel, traten postpunktionelle Kopfschmerzen auf (Strupp et al. 2001). Dies entspricht einer Reduzierung von $50 \%$ der postpunktionellen Kopfschmerzen. Der genaue Mechanismus des PPKS (oder auch Liquorunterdrucksyndrom) ist unbekannt. Neben der möglichen Entstehung eines Unterdruckes im Liquorraum (Verlust von Liquor durch die Einstichstelle der Nadel in den paraspinalen Bereich) werden zerebrale Gefäßerweiterungen und ein reduzierter venöser Abfluss als Ursachen angenommen (Wang und Schmidt 1997, Diener und Weimer 2012). Anmerkend sei gesagt, dass die ausgetretene Liquorvolumenmenge in den paraspinalen Bereich nicht mit dem Auftreten eines Liquorunterdrucksyndroms korreliert (lqbal et al. 1995). Postpunktioneller Kopfschmerz tritt häufiger bei jungen Frauen mit einem niedrigen Body Mass Index (BMI) und bei Patienten mit postpunktionellen Kopfschmerzen in ihrer Krankengeschichte auf (Evans et al. 2000). In anderen Studien war ebenso jüngeres Alter und zusätzlich keine vorherige Aspirineinnahme ein vermehrtes Risiko für das Auftreten von postpunktionellen Kopfschmerzen (Dakka et al. 2011). Daraus könnte sich eine Aspirineinnahme als prophylaktische Maßnahme vor einer Lumbalpunktion erschließen.

Rückenschmerzen sind weniger häufig, können aber bei bis zu $40 \%$ der Patienten mit Lumbalpunktion vorkommen (Flaatten et al. 1998). Seltene und unerwünschte Zwischenfälle sind Infektionen, intrakraniell-subdurale Blutungen und spinal-epidurale oder spinal-subarachnoidale Blutungen (Evans 1998). Lumbalpunktionen können mit einer geringen Rate an Nebenwirkungen auch bei älteren Erwachsenen durchgeführt werden (Hindley et al. 1995). 


\subsection{Einführung in die Liquordiagnostik}

Hier soll nur eine kurze Einführung in die Liquordiagnostik beschrieben werden. Genauere Informationen sind den „Leitlinien der Liquordiagnostik und Methodenkatalog der Deutschen Gesellschaft für Liquordiagnostik und Klinische Neurochemie" (herausgegeben von Petereit H-F, Sindern E und Wick M im Springer Verlag 2007) oder vergleichbaren Werken zu entnehmen. Nur die wichtigsten und gängigsten Methoden seien hier erwähnt und kurz beschrieben.

Zunächst muss die makroskopische Beurteilung des Liquor immer im Zusammenhang mit dem Punktionsort und dem Patientenalter stattfinden, da die chemische Zusammensetzung altersabhängig ist und kompartimentellen (äußere/innere Liquorräume, lumbale und kraniale Liquorverteilung) Variationen unterliegt (Conly und Ronald 1983). Es herrscht ein rostrokaudaler Konzentrationsgradient, der die Diffusion von Molekülen aus dem Blut in den lumbalen Liquor im Vergleich zur Diffusion im Bereich des kraniellen Liquors zirkulationsabhängig beeinflusst (Reiber 2003). Makroskopisch lässt sich der Liquor leicht beurteilen und erlaubt erste vage Rückschlüsse auf die Ursache der Verfärbung. Blutiger Liquor kann hinweisend auf eine akute Blutung in die Liquorräume sein, wie sie z.B. bei einer Subarachnoidalblutung auftritt. Aber auch durch die Punktion selbst kann es zu einer Blutbeimengung kommen, welche den Liquor blutig färbt und so zu einer Fehlinterpretation führen kann. Um eine schnelle Unterscheidung zwischen artifiziell-blutigem Liquor und blutigem Liquor durch Einblutung in die Liquorräume treffen zu können, hat sich die Durchführung der 3-Gläser-Probe bewährt (Masuhr und Neumann 2007). Hierbei werden drei sterile Liquorröhrchen (durchsichtig, unbeschichtet und konisch zulaufend aus Polystyrol) direkt aus der Punktionsstelle nacheinander mit jeweils 1$2 \mathrm{ml}$ Liquor gefüllt. Nimmt die Intensität der Blutbeimengung im Verlauf der drei Röhrchen ab, so ist von einer artifiziellen Blutbeimengung auszugehen. Nimmt die Intensität nicht ab, so ist dies hinweisend auf eine Blutung in die Liquorräume. Generell sollte blutiger Liquor schnellstmöglich bei 200-300 g zentrifugiert werden. Entsteht so ein klarer Überstand, ist dies ein weiteres Anzeichen einer artifiziellen Blutbeimengung. Zu beachten ist jedoch, dass auch nach einer kurz zurückliegenden 
Blutung der Überstand nach Zentrifugation klar sein kann. ${ }^{6}$ Bildet sich nach dem Zentrifugieren ein xanthochromer Überstand, kann dies für eine ältere Blutung sprechen. Aber auch bei einer starken Erhöhung der Eiweißkonzentration im Liquor (z.B. Polyradikulitis) und bei einer schweren Hyperbilirubinämie (Ikterus) findet sich ein xanthochromer Liquor (Storch-Hagenlocher 2006b, Masuhr und Neumann 2007) (Abbildung 4).

\section{Abbildung 4: Liquor makroskopisch}

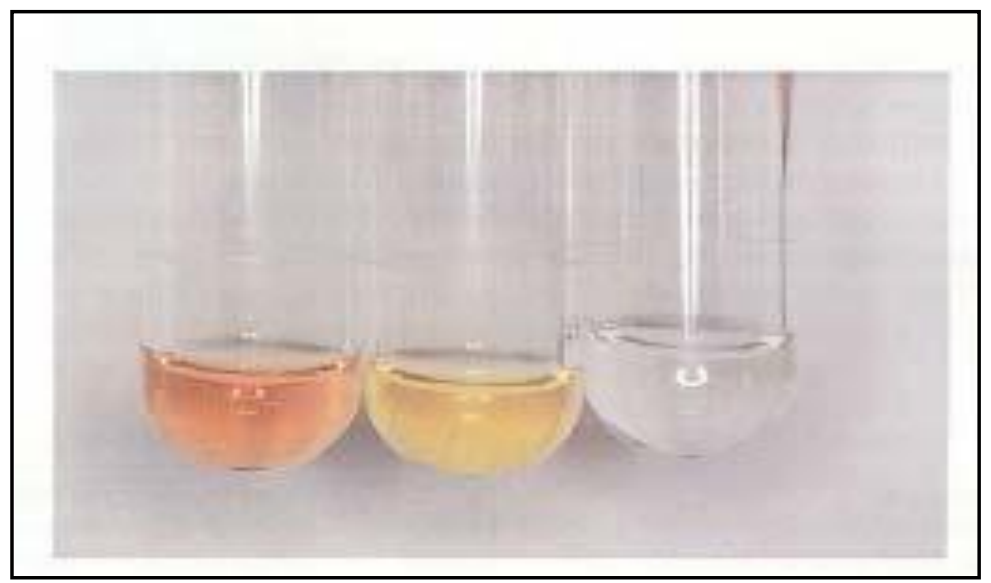

Links: xanthochromer Liquor nach Subarachnoidalblutung; Mitte: xanthochromer Liquor bei Polyradikulitis; Rechts: Liquor Normalbefund

(aus Masuhr und Neumann 2007, S. 125)

Ein trüb-flockiger Liquor spricht in der Regel für eine eitrige Meningitis und kommt durch starke Pleozytose (Zellzahlerhöhung im Liquor > $1000 \mu$ l) und Proteinerhöhung zustande. Auch eine isolierte Eiweißerhöhung kann den Liquor trüb verfärben. So genannte "Spinnwebgerinnsel" sind makroskopisch sichtbare grobe Fibringerinnsel, die häufig mit einer tuberkulösen oder Kryptokokken- (Cryptococcus neoformans) Meningitis assoziiert sind (Staib et al. 1990).

Die visuelle Beurteilung des Liquors ist somit eine schnelle und einfache Methode, um erste wegweisende Anhaltspunkte zu erlangen und eine zielgerichtete Anschlussdiagnostik folgen lassen zu können.

\footnotetext{
${ }^{6}$ Wie so oft in der Medizin bieten auch die 3-Gläser-Probe und die Zentrifugation keine 100-prozentige Spezifität. Ergebnisse einzelner Testverfahren müssen immer im Kontext mit anderen diagnostischen Methoden beurteilt werden, um ein individuelles Gesamtbild erstellen zu können.
} 
Die Zellzählung erfolgt mikroskopisch meistens mit Hilfe der Fuchs-RosenthalKammer $\left(3,2 \mu \mathrm{l}\right.$ Volumen, $16 \mathrm{~mm}^{2}$ Fläche, $0,2 \mathrm{~mm}$ Tiefe) nach Anfärbung mit Karbolfuchsinlösung. Hierzu wird nativer und möglichst frischer Liquor benötigt. Neben der manuellen Zellzählung am Mikroskop gibt es die Möglichkeit der automatisierten Zellzählung mit verschiedenen zytometrischen Systemen. Über die Analogie und Präzision der unterschiedlichen Systeme im Vergleich zur manuellen Zählung gibt es zahlreiche Untersuchungen (Hoffmann und Janssen 2002). Als Ergebnis steht fest, dass gegenwärtig die konventionelle mikroskopische liquorzytologische Differenzierung in keiner Weise von den vorliegenden Methoden der automatisierten Zelldifferenzierung ersetzt werden kann (Storch-Hagenlocher 2006b).

Zur Präanalytik gehört neben der konventionellen Zytologie auch die Immunzytologie. Analog zum Blut lässt sich aber nicht einfach ein Ausstrich anfertigen und untersuchen. Der fast zellfreie Liquor (Abschnitt 1.1 Liquor cerebrospinalis) bedarf fast immer der vorherigen Zellanreicherung. Hierbei ist besonders darauf zu achten, dass die Zellmorphologie erhalten bleibt und der Zellverlust minimal bleibt. Dies geschieht entweder durch die Methode des Sedimentierkammerverfahrens oder durch die Methode der Zytozentrifugation. Ein weiteres Vorgehen zur Steigerung der Zellausbeute ist die Vorzentrifugation bei ca. 2200 Umdrehungen/Minute (StorchHagenlocher 2006b).

Alle Verfahren besitzen Vor- und Nachteile (Tabelle 3), aber näher soll auf diese Verfahren hier nicht eingegangen werden. Erläuterungen über die für diese Studie verwendeten Verfahren siehe im Abschnitt 2.2 Labortests. 
Tabelle 3 : Vor- und Nachteile Zellanreicherungsverfahren

\begin{tabular}{|c|c|c|}
\hline Verfahren & Vorteile & Nachteile \\
\hline Sedimentierkammer & $\begin{array}{l}\text { - guter morphologischer } \\
\text { Zellerhalt, Zellen sind für die } \\
\text { Zytodiagnostik optimal zu } \\
\text { beurteilen }\end{array}$ & $\begin{array}{ll}\text { - } & \text { relativ großer Liquor- } \\
\text { bedarf } \\
\text { - } & \text { Zellverlust durch das } \\
\text { Absaugen mit dem } \\
\text { Filterpapier } \\
\text { - } \quad \text { zellfreier Liquoranteil } \\
\text { kann nicht für weitere } \\
\text { Untersuchungen } \\
\text { verwendet werden }\end{array}$ \\
\hline Zytozentrifugation & $\begin{array}{ll}\text { - } & \text { praktikablere Anwendung } \\
\text { - } & \text { Standardisierbarkeit der } \\
& \text { Zentrifugation } \\
\text { - } & \text { gute Zellausbeute } \\
\text { - } & \text { benötigtes Liquorvolumen ist } \\
& \text { klein }\end{array}$ & $\begin{array}{l}\text { - elliptisch auseinander- } \\
\text { gezogenes Zytoplasma, } \\
\text { ausgefranste Ränder } \\
\text { - } \text { bei Lymphozyten ver- } \\
\text { größerter } \\
\text { Zytoplasmasaum, } \\
\text { hervortretende Nucleoli }\end{array}$ \\
\hline Vorzentrifugation & $\begin{array}{ll}\text { - } & \text { sehr gute Zellausbeute } \\
\text { - } & \text { Möglichkeit, mehrere Se- } \\
\text { dimente anzufertigen } \\
\text { - } & \text { gesamter Überstand kann für } \\
\text { weitere Diagnostik verwendet } \\
\text { werden } \\
\text { - } \quad \text { zytoprotektiver Effekt des } \\
\text { Mediums }\end{array}$ & 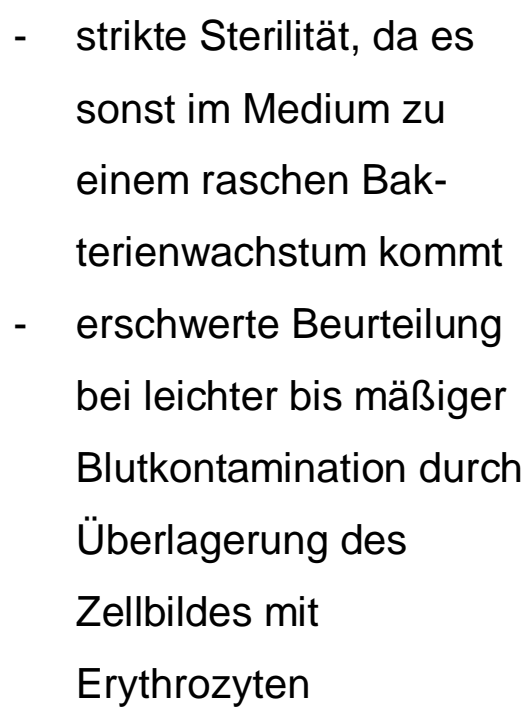 \\
\hline
\end{tabular}

(aus Storch-Hagenlocher 2006b) 
Anschließend folgt die Färbung (May-Grünwald-Giemsa-Färbung als Standard) und/oder Immunzytochemie des Präparates.

$\mathrm{Zu}$ den methodischen Grundlagen der Liquoranalytik gehören neben der Liquorzytologie auch die Immunchemie/Immunkomplex-Analytik, sowie die elektrophoretischen Nachweisverfahren. Die Immunchemie/Immunkomplex-Analytik dient zum spezifischen Nachweis von Markomolekülen (z.B. Proteine) in Geweben und Körperflüssigkeiten. Als Verfahren kommen u.a. die Nephelometrie und Turbidimetrie, Immunoassay, Agglutination und die radiale Immundiffusion und Elektroimmundiffusion zum Einsatz (Reiber 2006b). Die Eigenschaft der AntigenAntikörper-Bindung zu extrem stabilen Immunkomplexen nutzt man für diese Verfahren aus, um spezifische Epitope (Antigene) durch Hinzufügen von Antiseren (Antikörper) zu detektieren. Die elektrophoretischen Nachweisverfahren sind qualitative Methoden für den Nachweis von Proteinen in Serum und Liquor. Bei der Proteinelektrophorese werden Proteine auf einem Trägermaterial einem elektrischen Feld ausgesetzt. Abhängig u.a. von Molekülgröße, isoelektrischem Punkt, Temperatur und $\mathrm{pH}$-Wert des Puffers wandern die Proteine unterschiedlich weit und lassen sich so auswerten. Hat dieses Verfahren in der Labordiagnostik für Blutserum (Serumelektrophorese) noch einen hohen Stellenwert, so ist die Proteinelektrophorese für die Analytik des Liquors obsolet. Als Verfahren wurde hier die RocketElektrophorese (Elektroimmundiffusion) etabliert (Reiber 2006b). Die Isoelektrische Fokussierung ist eine weitere Methode der qualitativen Nachweisverfahren. Eine intrathekale IgG-Synthese (z.B. im Rahmen chronisch-entzündlicher Krankheiten, bei viralen und bakteriellen ZNS-Infektionen) lässt sich mit Hilfe der Isoelektrischen Fokussierung zuverlässig nachweisen, da sie eine sehr hohe Trennschärfe/Sensitivität besitzt (Wurster 2003). Jedes Protein besitzt einen bestimmten pH-Wert, an dessen Punkt die Nettoladung des Proteins gleich null ist, auch isoelektrischer Punkt genannt. In einem elektrischen Feld mit pH-Gradienten wandern die Proteine in einer Trägersubstanz (Agarosegel) je nach Ladung zur Anode bzw. Kathode. Erreichen sie ihren isoelektrischen Punkt, werden sie an dieser Stelle "fokussiert" und lassen sich so auswerten. Der Nachweis von oligoklonalen IgG-Banden im Liquor/Serum erfolgt nach der Isoelektrischen Fokussierung mit Hilfe des Immunoblot oder der Silberfärbung (Reiber 2006b). 


\subsection{Zielsetzung}

Die Bestimmung der Liquorlaktatkonzentration gehört in der Liquoranalytik zur Routinediagnostik. Wie bereits beschrieben (Abschnitt 1.1 Liquor cerebrospinalis), ist die Laktatkonzentration im Liquor altersabhängig und erlaubt Rückschlüsse auf die Genese insbesondere von entzündlichen ZNS-Erkrankungen. Die Studienlage ist hierzu allerdings sehr gering und vor allem die Untersuchungen an einem geriatrischen Patientenkollektiv bisher sehr selten.

Voraussetzung für die Liquoranalytik (Abschnitt 1.3 Einführung in die Liquordiagnostik) ist meistens die Durchführung einer Lumbalpunktion (Abschnitt 1.2 Lumbalpunktion), die mit einem geringen Risiko an schwerwiegenden Komplikationen einhergeht. Aber im Gegensatz zu der Datenlage über die Laktatkonzentrationen im Liquor findet man gehäuft in der Literatur Studien über Komplikationen der Lumbalpunktion (Hindley et al. 1995, Strupp et al. 2001), auch wenn hier wiederum die Untersuchungen an einem geriatrischen Patientenkollektiv unterrepräsentiert sind. In der Literatur wird von „erhöhtem Alter" (Dakka et al. 2011, Armon und Evans 2005) oder "älteren Erwachsenen" (Hindley et al. 1995) berichtet, aber spezielle Untersuchungen an einem geriatrischen Patientenkollektiv (Alter $\geq 65$ Jahre) sind verschwindend gering.

U.a. aufgrund der möglichen Komplikationen (Abschnitt 1.2 Lumbalpunktion) sollte eine Lumbalpunktion, wie jeder invasive Eingriff, einer strengen Indikation unterliegen (Tabelle Abschnitt 1.2 Lumbalpunktion). Hieraus erschließen sich die Fragen, in wie vielen Fällen sich die Indikation/Verdachtsdiagnose mit der letztendlichen Diagnose deckt, ob es liquoranalytisch andere Ursachen für die jeweilige klinische Erscheinung des Patienten gab oder ob sich gar ein völlig unauffälliger Liquorbefund darstellte. Des Weiteren liegt die Frage nach Prävalenz und Art von Komplikationen nahe. 
Aufgrund dieser Fragen und der dürftigen Datenlage sind Ziele der vorliegenden retrospektiven Studie:

1. Darstellung des Verhältnisses von Laktatkonzentration zu Patientenalter bei nicht entzündlich verändertem Liquor

2. Analyse von Liquor-Routineparametern eines geriatrischen Patientenkollektivs

3. Ermittlung der häufigsten Indikationen zur Lumbalpunktion eines geriatrischen Patientenkollektivs innerhalb von 4 Jahren

4. Untersuchung der Übereinstimmung von Indikation vor Lumbalpunktion und Diagnose nach Lumbalpunktion eines geriatrischen Patientenkollektivs innerhalb von 4 Jahren

5. Untersuchung von Komplikationen nach einer Lumbalpunktion in einem geriatrischen Patientenkollektiv innerhalb von 4 Jahren 


\section{Material und Methoden}

\section{$2.1 \quad$ Patientenkollektiv}

Erstellt wurde eine Liste von 203 Patienten, die sich im Zeitraum von 2008 bis 2011 in der Abteilung Geriatrie und der Abteilung Innere Medizin des Evangelischen Krankenhauses Weende-Göttingen einer Lumbalpunktion unterzogen hatten. Unterteilt/Unterschieden wurde die Studiengruppe in Patienten älter als 65 Jahre und Patienten jünger als 65 Jahre, die eine therapeutische oder diagnostische Lumbalpunktion im Rahmen ihrer klinischen Routine erhalten hatten. Verwendete und ausgewertete Informationen aus den jeweiligen Arztbriefen der Patienten vom Zeitraum, in dem die Lumbalpunktion durchgeführt wurde, beinhalteten Alter, Geschlecht, Fieber, neurologische und psychische Symptome einschließlich kognitiver Beeinträchtigung mit oder ohne eingeschränktem Bewusstsein, Komplikation der Lumbalpunktion, Aufnahmediagnose und Grund für die Durchführung der Lumbalpunktion. Eine Selektion von Patienten fand nicht statt. Anhand dieser Liste und der damit verbundenen Informationen wurde eine retrospektive Studie angelegt, deren Schwerpunkt die Untersuchung an einem geriatrischen Patientenkollektiv darstellt. Die Einverständniserklärung für die Lumbalpunktion wurde von allen Patienten oder ihren Betreuern inhaltlich und formal korrekt eingeholt.

Die Studie wurde von der Ethikkommission der Universitätsmedizin Göttingen als ethisch unbedenklich begutachtet.

\section{$2.2 \quad$ Labortests}

\subsubsection{Fuchs-Rosenthal-Zählkammer und Zelldifferenzierung}

Mit Hilfe der Fuchs-Rosenthal-Zählkammer wurde am gefärbten (Karbolfuchsinlösung) Liquor die Zellzahl ermittelt (Pleozytose ist definiert als $>4$ Zellen/ $\mu$ l). Nach anschließender Zellanreicherung des nativen Liquors (Zentrifuge Omnifuge 2.0 ORS der Firma Thermo Scientific, mit 700 Umdrehungen/min für $10 \mathrm{~min}$ bei $21^{\circ} \mathrm{C}$ ) und Färbung (May-Grünwald-Giemsa-Färbung) folgte die Differenzierung der einzelnen Zellen per Mikroskop in Lymphozyten, Monozyten, Granulozyten und Erythrozyten, 
der Nachweis anderer Zellen wie z.B. Tumorzellen, Chondrozyten oder Epithelzellen wurde zusätzliche befundet.

\subsubsection{May-Grünwald-Giemsa-Färbung}

Nach Zellanreicherung durch Zytozentrifugentechnik folgte die Fixierung und Färbung der Zellpräparate mittels May-Grünwald-Giemsa-Färbung (Firma Merck, Darmstadt, Deutschland). Hierzu muss man die May-Grünwald-Eosin-Methylenblaulösung auf die Zellpräparate auftragen und 2 min einwirken lassen. Anschließend muss man $1 \mathrm{ml}$ Pufferlösung nochmals $1 \mathrm{~min}$ einwirken lassen und danach abgießen. Danach folgt die Einwirkung von verdünnter Giemsa-Azur-Eosin-Methylenblaulösung (auf $10 \mathrm{ml}$ Pufferlösung 15 Tropfen Giemsa-Lösung) über 8 min und ein Abspülen mit $\mathrm{H}_{2} \mathrm{O}$. Nach 15 min Trocknungszeit werden die Präparate mit einem Eindeckmittel (Depex, Fa. Serva, Heidelberg, Deutschland) abgedeckt.

\subsubsection{Gesamtprotein}

Das Gesamtprotein wurde anhand der kinetischen Auswertung der maximalen Streulichtintensität in $40 \%$ iger TCA-Lösung bestimmt (Gerät Dosascat der Firma Dosatec® $\mathrm{GmbH}$, Gilching, Deutschland) (Reiber 1980).

\subsubsection{Albumin}

Das Verfahren der immunchemischen Nephelometrie mit Zweipunkt- oder kinetischer Analytik diente dem Nachweis von Albumin (Gerät $\mathrm{BN}^{\circ}$ ProSpec des Herstellers Siemens Healthcare Diagnostics Inc., Terrytown, New York, USA).

\subsubsection{IgG IgA und IgM im Liquor und Serum}

Die Liquor- und Serumkonzentrationen von $\lg G$, $\lg A$, und $\lg M$ wurden nephelometrisch (immunchemische Detektionsverfahren) bestimmt (Gerät BN ProSpec des Herstellers Siemens Healthcare Diagnostics Inc., Terrytown, New York, USA) und daraus das Liquor/Serum Verhältnis für $\lg G$, $\lg A$, $\lg M$ und Albumin berechnet. Das IgG-, IgA-, und IgM- Liquor/Serum-Verhältnis wurde gegen das Liquor/Serum- 
Albumin-Verhältnis ( $Q_{\text {Albumin }}$ ) entsprechend dem Nomogramm von Reiber und Felgenhauer aufgezeichnet (Reiber und Felgenhauer 1987). Der altersabhängige Referenzbereich für $Q_{\text {Albumin }}$ wurde berechnet als $Q_{\text {Albumin }}=(4+$ Alter/15 $) \times 10^{-3}$ (Reiber et al. 2001).

\subsubsection{Laktat}

Zur Laktatbestimmung (pathologische Werte altersabhängig, siehe Abschnitt 1.1 Liquor cerebrospinalis) wurde die enzymatische Methode mittels Laktat-Oxydase angewendet. Hierbei spaltet die Laktat-Oxydase Laktat in Pyruvat und Wasserstoffperoxyd. Durch weitere Zwischenreaktionen entwickelt sich zum Schluss ein rot gefärbtes Chinonimin, dessen Farbintensität proportional zur Laktatkonzentration ist. Die Farbintensität wurde mit dem ELISA-Reader von SLT/Easy-Fit Programm mit Referenzfilter 620 nm gemessen.

\subsubsection{Intrathekales oligoklonales IgG}

Das Prinzip der Isoelektrischen Fokussierung wurde benutzt, um eine intrathekale oligoklonale IgG-Synthese nachzuweisen. Um die Banden im Liquor und Serum vergleichen zu können, wurden Liquor und Serum so verdünnt, dass gleiche IgGMengen aufgetragen wurden (Reiber und Felgenhauer 1987).

\subsubsection{Erregerspezifische Antikörper}

Erregerspezifische Antikörper (z.B. Masern-lgG) wurden auf Anforderung des behandelnden Arztes mit Hilfe des erregerspezifischen Antikörper-Index (Al) bei Patienten mit pathologischen Leukozytenzahlen und/oder bei Patienten mit positiven oligoklonalen Banden gemessen (verwendet wurden die Testkits der Firma Siemens Healthcare Diagnostics GmbH, Marburg, Deutschland). Der Antikörper-Index wurde anhand der Formel ( $\left.\lg _{\text {spezifische AK im Liquor }} / \lg _{\text {spezifische AK im Serum }}\right) /\left(\lg _{\text {Liquor total }} / \lg _{\text {Serum total }}\right)$ berechnet. Im Falle einer durch das Reiber-Felgenhauer-Nomogramm erfassten gesamten IgG- oder IgM-Synthese wurde der Nenner der Antikörper-Index-Formel $\lg _{\text {Liquor total }} / \lg _{\text {Serum total }}$ durch $Q_{\text {lim }}$ ersetzt. $Q_{\text {lim }}$ ist das maximale Verhältnis von Ig Liquor total/Igserum total, welches bei einem angegebenen Liquor-/Serum-Albumin-Quotienten 
ohne intrathekal synthetisierte Immunoglobuline erwartet werden kann (Durchschnitt +3 Standartabweichungen) (Reiber und Lange 1991). Der Antikörper-Index ist definiert als pathologisch (hinweisend auf eine Antikörpersynthese gegen ein spezifisches Antigen innerhalb des Liquors), wenn er $\geq 1.5$ ist.

\subsubsection{Demenzmarker}

Bei einigen Patienten mit kognitiver Beeinträchtigung wurde die Gesamtkonzentration des Tau-Protein (tau-protein), des phosphorylierten Tau-Proteins (phospho-tau) und des beta-Amyloid-Peptids 1-42 (Abeta 1-42) durch Enzymimmunoassays (Innogenetics, Hannover, Deutschland) bestimmt.

\subsection{Statistik}

Statistische Berechnungen wurden mit GraphPad Prism Software (GraphPad Software, La Jolla, USA) erstellt. Normverteilte Daten wurden dargestellt als Mittelwert \pm Standardabweichung (SD), nicht normverteilte als Median und Interquartilsabstand (75\% und $25 \%$ Perzentile). Um abschätzen zu können, ob die Werte normalverteilt waren, wurde der D'Agostino-Pearson-Test verwendet. Univariate Analysen für normalverteilte Daten wurden mit Hilfe des t-Tests unabhängiger Stichproben ausgewertet und für nicht normalverteilte Daten wurde der U-Test benutzt. Korrelationen (für parametrische Daten mit dem Pearson's Korrelationskoeffizienten $r$, für nicht-parametrische Daten mit dem Spearman's Rangkorrelationskoeffizient $r_{s}$ ) zwischen den Parametern wurden ebenso ausgewertet. P-Werte $\leq 0.05$ wurden als statistisch signifikant angenommen. 


\section{Ergebnisse}

\subsection{Verdachtsdiagnosen und Liquorbefunde}

Zwischen 2008 und 2011 wurde bei 203 Patienten der Abteilungen Geriatrie und Innere Medizin des Evangelischen Krankenhaus Göttingen-Weende eine Lumbalpunktion durchgeführt. Das Durchschnittsalter dieser Patienten lag bei 72,5 \pm 16,4 Jahren und das Geschlechterverhältnis bei 114 Frauen (56,2 \%) zu 89 Männern $(43,8 \%)(F / M) .36$ Patienten (17,7\%) waren jünger als 65 Jahre (F/M 17/19).

Tabelle 4: Klinische Kenndaten der Patienten älter und jünger als 65 Jahre

\begin{tabular}{|c|c|c|c|}
\hline Parameter & $\begin{array}{l}\text { Alle Patienten } \\
\qquad(n=203)\end{array}$ & $\begin{array}{c}\text { Patienten } \geq 65 \mathrm{~J} \\
(\mathrm{n}=167)\end{array}$ & $\begin{array}{l}\text { Patienten < } 65 \mathrm{~J} \\
(\mathrm{n}=36)\end{array}$ \\
\hline Alter & $72.9 \pm 16.4$ & $79.4 \pm 7.0$ & $42.4 \pm 11.7$ \\
\hline Geschlecht (F/M) & $113 / 90$ & $96 / 71$ & $17 / 19$ \\
\hline \multicolumn{4}{|c|}{ Symptome bei Aufnahme/vor Lumbalpunktion } \\
\hline Dysästhesie & 25 & 14 & 11 \\
\hline Kopfschmerzen & 14 & 7 & 7 \\
\hline Fieber & 38 & 29 & 9 \\
\hline Sehstörungen & 15 & 7 & 8 \\
\hline $\begin{array}{l}\text { Psychiatrische } \\
\text { Symptome }\end{array}$ & 164 & 153 & 11 \\
\hline
\end{tabular}


Eine Übersicht über Alter, Geschlecht und klinische Symptome von allen an der Studie teilgenommenen Patienten ist in Tabelle 4 aufgelistet. Die klinischen Symptome beziehen sich auf den Zeitpunkt vor der Lumbalpunktion. Patienten jünger als 65 Jahre litten am häufigsten an Dysästhesie und psychiatrischen Symptomen mit jeweils $30,5 \%$, gefolgt von Sehstörungen mit 22,2\%. Auch bei den Patienten über 65 Jahre waren die psychiatrischen Symptome führend, jedoch mit 91,6\% deutlich stärker repräsentiert als bei den Patienten jünger als 65 Jahre. Weitere 17,4 \% der Patienten über 65 Jahren zeigten initial Fieber bei der Aufnahme.

Die häufigste Indikation zur Durchführung einer Lumbalpuktion (Abbildung 5) aus diesem Patientenkollektiv war der Verdacht einer Infektion des Zentralnervensystems (ZNS), gefolgt von der Verdachtsdiagnose einer Demenz und die therapeutische Durchführung eines Liquorablassversuchs bei Normaldruckhydrozephalus (NPH).

Abbildung 5: Verdachtsdiagnosen (= Indikation für Liquoranalyse) des Patientenkollektivs



Die häufigste Ursache für eine Lumbalpunktion war eine vermutete ZNS-Infektion, gefolgt von Demenz und Normaldruckhydrozephalus (NPH). Bei jüngeren Patienten war die Frage nach chronischen Autoimmunerkrankungen der häufigste Grund für eine Lumbalpunktion. 
Die weiteren Verdachtsdiagnosen sind der oben angegebenen Abbildung $5 \mathrm{zu}$ entnehmen.

Bei 110 Patienten mit Verdacht auf Infektion des ZNS wurde nur in einem Fall eine bakterielle Meningitis (BM) diagnostiziert, bei neun (8,2\%) eine virale Meningitis (VM) und in zwei Fällen (1,82\%) eine Herpes-Simplex-Virus (HSV)-Enzephalitis. Beide Patienten mit HSV-Enzephalitis waren jünger als 65 Jahre. Im Liquor des Patienten mit bakterieller Meningitis, der älter als 65 Jahre war, konnte Listeria monocytogenes kultiviert werden. Vier von den neun Patienten mit viraler Meningitis hatten eine Varizella-Zoster-Virus (VZV)-Meningitis und waren älter als 65 Jahre. Zwei dieser Patienten mit VZV-Erkrankung zeigten kein begleitendes Zosterexanthem. Ein Patient, jünger als 65 Jahre und an dem Acquired Immune Deficiency Syndrome (AIDS) erkrankt, litt unter Cryptococcus neoformans-Meningitis. Lyme-Neuroborreliose konnte bei keinem Patienten über 65 Jahre diagnostiziert werden, aber bei einem Patienten unter 65 Jahre. Zwei Patienten, beide jünger als 65 Jahre, waren an Enzephalomyelitis disseminata (ED) erkrankt und ein Patient, ebenfalls jünger als 65 Jahre, an transverser Myelitis (TM).

Insgesamt konnte bei 8 von 167 Patienten (4,8\%), die älter als 65 Jahre waren und mit Verdacht auf Entzündung des ZNS lumbal punktiert wurden, und bei 2 von 36 Patienten (5,6\%) jünger als 65 Jahre mit Verdacht auf Entzündung des ZNS die Diagnose durch Untersuchung des Liquors bestätigt werden. Außerdem konnte ein entzündliches Geschehen im ZNS durch Liquoranalyse bei 3 von 167 Patienten $(1,8 \%)$ älter als 65 Jahre und bei einem von 36 Patienten (2,8\%) jünger als 65 Jahre festgestellt werden, ohne dass ein klinischer Verdacht auf Entzündung des ZNS vor der Lumbalpunktion bestanden hatte.

Erhöhte Laktatkonzentrationen ( $\geq 2.4 \mathrm{mmol} / \mathrm{l})$ ohne meningeale Entzündung wurden bei 10 Patienten älter und nur bei einem Patienten jünger als 65 Jahre gefunden. Die durchschnittliche Liquorlaktatkonzentration bei Patienten älter als 65 Jahre (1.7 \pm $0.5 \mathrm{mmol} / \mathrm{l})$ war geringfügig, aber signifikant höher $(p<0.001)$ als die durchschnittliche Liquorlaktatkonzentration jüngerer Patienten unter 65 Jahre (1.3 $\pm 0,3 \mathrm{mmol} / \mathrm{l})$, die keine meningeale Entzündung aufwiesen. Die Laktatkonzentration im Liquor bei Patienten mit sonst normalen Lumbalpunktions-Befunden (LP-Befund) korrelierte signifikant mit dem Alter der Patienten (Abbildung 6). 


\section{Abbildung 6: Die Liquorlaktatkonzentration in Abhängigkeit vom Alter bei Patienten ohne entzündliche ZNS-Erkrankungen}

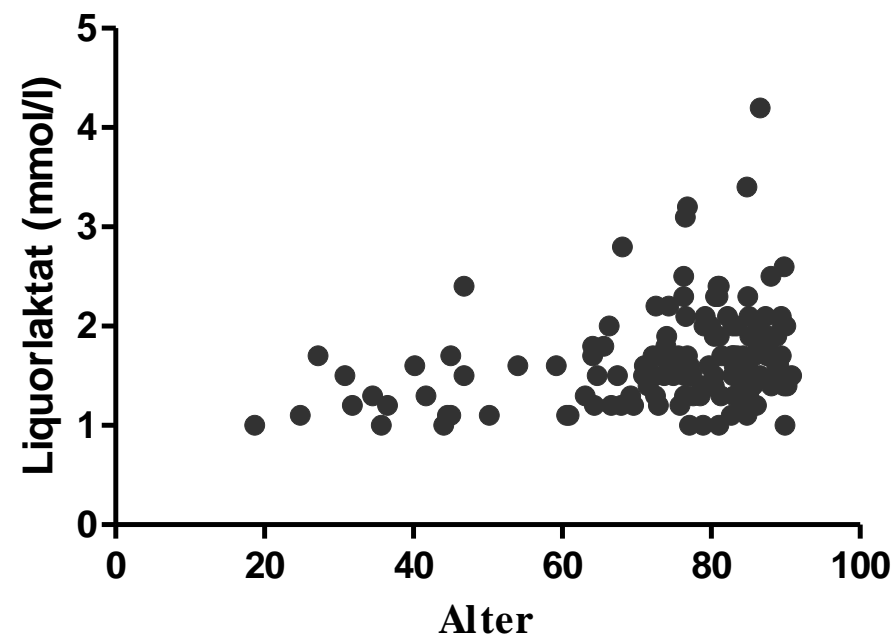

Die Liquorlaktatkonzentration bei Patienten ohne Nachweis einer entzündlichen ZNS-Erkrankung $(n=144)$ korrelierte mit dem Alter $\left(p=0.0012 ; r_{s}=0.27\right)$

Von 33 Patienten mit der Verdachtsdiagnose Demenz wurden bei 17 Patienten die Liquordemenzmarker Abeta 1-42, tau-protein und phospho-tau bestimmt. 14 dieser Patienten zeigten pathologische Ergebnisse, Abeta 1-42 war in neun Fällen erniedrigt, tau-protein in vier Fällen und phospho-tau in 3 Fällen erhöht.

Eine intrathekale Immunglobulinsynthese, abgeschätzt mit Hilfe des ReiberFelgenhauer-Normogramms, wurde nur bei einem Patienten mit LymeNeuroborreliose ( $\operatorname{lgM})$ und bei einem Patienten mit ED ( $\lg G)$ nachgewiesen. Intrathekale Synthese von IgA konnte im gesamten Patientenkollektiv nicht gefunden werden.

Die Isoelektrische Fokussierung, sensitiver als das Reiber-FelgenhauerNormogramm, ergab oligoklonale IgG-Banden (OKB), hinweisend auf eine lgGSynthese im Liquor, bei 9 von 105 Patienten älter als 65 Jahre (8.6\%) und bei 2 von 34 Patienten jünger als 65 Jahre (6.3\%). 62 Patienten älter als 65 Jahre und 4 Patienten jünger als 65 Jahre wurden nicht auf OKB getestet. Im Gegensatz zu jungen Patienten, bei denen chronisch-entzündliche Erkrankungen hauptsächlich Grund für positive OKBs sind, beobachteten wir eine intrathekale IgG-Synthese bei geriatrischen Patienten im Falle von erregerbedingten ZNS-Infektionen. OKBs im 
Liquor bei Patienten mit ansonsten unauffälligen Liquorbefunden konnten nicht gefunden werden.

Das Verhältnis zwischen Liquor- und Serum-Albumin ( Qlbumin $_{\text {}}$ gilt als bester Marker, um die Permeabilität der Blut-Liquor-Schranke für Proteine aus dem Blut im Liquor zu charakterisieren; dies liegt an der Gegebenheit, dass Albumin im Liquor ausschließlich aus dem Blut stammt (Jesse et al. 2011). Bei fehlender Entzündung war $Q_{\text {Albumin }}$ bei 38 Patienten (18.7\%) des Kollektivs erhöht. Nur 6 dieser Patienten waren jünger als 65 Jahre, und im Durchschnitt war das $Q_{\text {Albumin }}$ signifikant höher bei Patienten älter als 65 Jahre (Tabelle 5).

Tabelle 5: Liquorbefunde der Patienten über und unter 65 Jahre ohne nachgewiesene Hirnhautentzündung

\begin{tabular}{|c|c|c|c|c|}
\hline $\begin{array}{l}\text { Laborparameter } \\
\text { im Liquor }\end{array}$ & $\begin{array}{c}\text { Alle Patien- } \\
\text { ten } \\
(n=186)\end{array}$ & $\begin{array}{c}\text { Patienten } \geq 65 J \\
(n=156)\end{array}$ & $\begin{array}{l}\text { Patienten }<65 \mathrm{~J} \\
(\mathrm{n}=30)\end{array}$ & $p$ \\
\hline 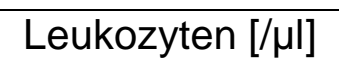 & $1.0(0 ; 2.0)$ & $1.0(0.0 ; 2.0)$ & $1.0(1.0 ; 2.0)$ & 0.42 \\
\hline $\begin{array}{c}\text { Gesamtprotein } \\
{[\mathrm{mg} / \mathrm{l}]}\end{array}$ & $\begin{array}{l}410.5 \\
(311.8 ; \\
571.8)\end{array}$ & $\begin{array}{c}430.5(323 ; \\
576.5)\end{array}$ & $\begin{array}{c}331.0(285 ; \\
541.5)\end{array}$ & 0.06 \\
\hline$Q_{\text {Albumin }} \times 10^{-3}$ & $\begin{array}{c}7.6(5.5 ; \\
10.3)\end{array}$ & $8.1(6.1 ; 10.5)$ & $4.8(4.2 ; 7.9)$ & $0.001^{*}$ \\
\hline $\begin{array}{l}\text { Liquorlaktatkon- } \\
\text { zentration } \\
{[\mathrm{mmol} / \mathrm{l}]}\end{array}$ & $\begin{array}{c}1.6(1.3 ; \\
1.9)\end{array}$ & $1.6(1.4 ; 1.9)$ & $1.25(1.1 ; 1.5)$ & $<0.0001^{*}$ \\
\hline
\end{tabular}

Vergleich der Liquorparameter bei alten und jungen Patienten. Dargestellte Werte sind Median und 75\%- und 25\%-Perzentile (Q25 und Q75). Der Mann-Whitney-U-Test wurde angewandt. Ein signifikanter Unterschied* zwischen den Gruppen wurde für $\mathrm{Q}_{\text {Albumin }}$ und die Liquorlaktatkonzentration gefunden. 
Die Serumkonzentrationen von Albumin, $\lg G$, $\lg A$ und $\lg M$ sind in Tabelle 6 zusammengefasst. Bei Patienten älter als 65 Jahre zeigte sich eine signifikante Erniedrigung der Albumin-Serumkonzentration und eine signifikante Erhöhung der IgA-Konzentration im Vergleich zu den Patienten jünger als 65 Jahre.

Tabelle 6: Serumkonzentration von Albumin, IgG, IgA und IgM bei Patienten älter und jünger als 65 Jahre

\begin{tabular}{|c|c|c|c|c|}
\hline Parameter & $\begin{array}{l}\text { Alle Patienten } \\
\qquad(\mathrm{n}=186)\end{array}$ & $\begin{array}{l}\text { Patienten } \geq 65 \mathrm{~J} \\
\qquad(\mathrm{n}=156)\end{array}$ & $\begin{array}{l}\text { Patienten }<65 \mathrm{~J} \\
\qquad(\mathrm{n}=30)\end{array}$ & $p$ \\
\hline $\begin{array}{c}\text { Albumin } \\
\text { [g/l] }\end{array}$ & $33.4(26.4 ; 38.3)$ & $32.2(25.9 ; 36.9)$ & $39.9(33.0 ; 43.4)$ & $<0.0001^{*}$ \\
\hline $\lg G[g / l]$ & $9.7(7.8 ; 11.3)$ & $9.5(7.7 ; 11.2)$ & $10.3(8.3 ; 11.3)$ & 0.27 \\
\hline $\lg A[g / l]$ & $2.6(1.7 ; 3.8)$ & $2.7(1.7 ; 4.1)$ & $2.1(1.4 ; 2.9)$ & $0.04^{*}$ \\
\hline $\lg M[g / l]$ & $0.9(0.6 ; 1.4)$ & $0.87(0.56 ; 1.3)$ & $0.9(0.63 ; 1.6)$ & 0.35 \\
\hline
\end{tabular}

Vergleich der Laborparameter bei alten und jungen Patienten. Dargestellte Werte sind Median und 75\%- und 25\%-Perzentile (Q75 und Q25). Der Mann-Whitney-U-Test wurde angewandt. Ein signifikanter Unterschied* $z$ wischen den Gruppen wurde für Albumin- und IgA-Konzentrationen im Serum gefunden. 
Bei 27 Patienten mit Verdacht auf Normaldruckhydrozephalus wurde eine Lumbalpunktion mit ca. $40 \mathrm{ml}$ Liquorablass durchgeführt. Bei 10 dieser Patienten (37\%) konnte eine Verbesserung des Gangbildes und der neuropsychologischen Funktionen beobachtet werden. Zwei von diesen Patienten erhielten einen ventrikuloperitonealen Shunt.

Postpunktioneller Kopfschmerz (PPKS) wurde nur bei einem Patienten jünger und einem Patienten älter als 65 Jahre dokumentiert. Des Weiteren wurde kein ernsthafter Zwischenfall beobachtet, insbesondere keine Infektionen und keine intrakraniellen Subduralblutungen bei Patienten nach Lumbalpunktion. 


\section{Diskussion}

Liquorroutineparameter sind integraler Bestandteil der therapeutischen und diagnostischen Verfahren bei geriatrischen Patienten und bilden die Basis für weitere krankheitsspezifische Untersuchungen. Altersabhängige und kompartimentelle Variationen in der chemischen Zusammensetzung sind wichtig für die Interpretation der Ergebnisse (Conly und Ronald 1983). Um die Indikation für eine Lumbalpunktion in unserem geriatrischen Kollektiv ermitteln zu können, um häufige Komplikationen nach einer Lumbalpunktion zu definieren und um herauszufinden, wie sich die Liquorzusammensetzung in einem multimorbid-geriatrischen Kollektiv verändert, analysierten wir retrospektiv Routine-Liquorbefunde, gesammelt über vier Jahre in unserer Klinik.

Die Lumbalpunktion ist eine wichtige diagnostische Untersuchung für die Evaluation von autoimmun-entzündlichen Geschehen, Infektionen, Subarachnoidalblutungen, Neoplasien und neurodegenerativen Erkrankungen (Daube et al. 1993). Die weitaus häufigste Verdachtsdiagnose in unserem geriatrischen Kollektiv war die Frage nach einer Infektion des ZNS. Diese Diagnose konnte passend zu den Angaben in der Literatur (Statistisches Bundesamt 2011) in 12.7\% unserer Patienten bestätigt werden.

In unserem Patientenkollektiv wurde eine virale ZNS-Infektion häufiger als eine bakterielle ZNS-Infektion gefunden. Dies stimmt mit der Inzidenz von bakteriellen und viralen ZNS-Infektionen in der Literatur überein (Rotbart 2000). Wie schon von anderen berichtet (Biesiada et al. 2010), wurde eine Varizella-Zoster-Virus (VZV)Meningitis in unserem Patientenkollektiv ebenfalls nur bei Patienten über 65 Jahre gefunden. Erniedrigte zelluläre Immunität, ausgelöst durch Stress, Steroide oder Immunsuppressiva, geht nicht selten mit einer Herpes-Zoster-Infektion einher (Tavazzi et al. 2008). Bei unseren vier Patienten mit VZV-Meningitis konnte keiner dieser immunsuppressiven Umstände festgestellt werden. Das Alter stellt den höchsten Risikofaktor für einen Herpes Zoster und/oder eine VZV-ZNS-Infektion dar (Tavazzi et al. 2008). Ebenfalls bedeutend für die Entstehung einer VZV-ZNS- 
Infektion ist die Nähe des Zosterexanthems zum ZNS, denn je näher sich das betroffene Dermatom im Rahmen von Herpes-Zoster-Infektion zum ZNS befindet (z.B. Hals/Nacken), desto wahrscheinlicher ist es, dass der Patient Symptome einer ZNS-Beteiligung zeigt (Cunha et al. 2011). Zwei unserer Patienten mit VZVMeningitis zeigten jedoch kein begleitendes Zosterexanthem. Bereits 1998 wurde in der Literatur ein Fall von lokaler VZV-assoziierter Vaskulitis der Arteria cerebri media ebenfalls ohne Nachweis eines Zosterexanthems beschrieben ( $\mathrm{Nau}$ et al. 1998). Dies steht in Übereinstimmung mit mehreren früheren Untersuchungen (Ratzka et al. 2006, Nagel et al. 2008). Aufgrund dieser Möglichkeit, unter einer VZV-Meningitis auch ohne Manifestation eines Zosterexanthems zu leiden, sollte bei klinischen Symptomen einer viralen Meningitis insbesondere bei immunsupprimierten Patienten auch an eine Genese durch Varizella-Zoster-Virus gedacht werden.

Aus diesen Gründen sollte aus dem Nichtvorhandensein eines Zosterexanthems kein Ausschluss einer Varizella-Zoster-Virus-Infektion bei entsprechender Symptomatik resultieren. Zusammenfassend können dies u.a. die Ursachen dafür sein, dass VZVZNS-Infektionen nicht immer erkannt werden und somit unterdiagnostiziert sind.

Unter normalen physiologischen Bedingungen wird Liquorlaktat in den ZNSKompartimenten produziert und wird nicht durch die Laktatkonzentration im Blut signifikant beeinflusst, so dass die Liquorlaktatkonzentration weitgehend unabhängig von der Serumkonzentration ist. Eine Ausnahme besteht bei systemischer Laktatazidose (Reiber 2006c). Neurone und Leukozyten produzieren durch anaerobe Glykolyse den Hauptteil des Liquorlaktats (Wellmer et al. 2001). Erhöhtes Laktat im Liquor ist nicht spezifisch für eine bestimmte Krankheit (Reiber 2006c). Selbst bei bakteriellen Meningitiden stammen über $95 \%$ des Liquorlaktats von dem Wirt selber und nicht von den Bakterien im Liquor (Wellmer et al. 2001). Erhöhte Laktatkonzentrationen wurden u.a. aber auch bei Morbus Alzheimer (Parnetti et al. 1995), bei akut ischämischem Schlaganfall (Brouns et al. 2008), bei Meningeosis carcinomatosa (Hornig et al. 1983) und mitochondrialen Erkrankungen, besonders mit neuropsychiatrischen Symptomen (Finsterer 2001), beschrieben. Übereinstimmend mit vorherigen Beobachtungen (Lehmnitz et al. 2005) fanden wir, dass die Laktatkonzentration im Liquor bei Patienten ohne ZNS-Entzündung signifikant mit dem Alter der Patienten korreliert. Somit ist eine Erhöhung der Laktatkonzentration im Alter per se nicht immer als pathologisch einzustufen, sondern bedarf einer 
Komplementierung durch das klinische Bild des Patienten, also einer Beurteilung der Symptome des Patienten und ggf. weiterer Diagnostik.

Ein hoher Prozentsatz unserer Patienten litt unter Multimorbidität. Dieses lässt einen erhöhten anaeroben Metabolismus in den einzelnen ZNS-Kompartimenten der älteren Menschen vermuten, insbesondere bei Patienten mit zusätzlichen kardiovaskulären oder ZNS-Erkrankungen. Dies könnte eine zusätzliche Erhöhung der Laktatkonzentration im Alter begünstigen und sollte, wie oben beschrieben, in einem Gesamtkontext betrachtet werden.

Auch die Beurteilung der Blut-Liquor-Schranken-Funktion erlaubt Rückschlüsse auf verschiedene Erkrankungen und wurde von uns untersucht. Eine Blut-LiquorSchranken-Störung kann bei verschiedenen neurologischen Erkrankungen entzündlicher oder nicht entzündlicher Genese gefunden werden, wurde aber auch in Vorarbeiten bei Patienten ohne neurologische Erkrankungen beschrieben (Brettschneider et al. 2005). Das Liquor/Serum-Albumin-Verhältnis $\left(Q_{A l b u m i n}\right)$ steigt mit dem Alter in einer gesunden Bevölkerung an (Blennow et al. 1993). Bei älteren Menschen findet man häufig eine Erhöhung des $Q_{\text {Albumin. Dies kann aus einer }}$ generellen Verringerung des Liquorflusses entstehen oder aus einer Abnahme der spinalen Liquorzirkulation, basierend auf degenerativen Erkrankungen der Wirbelsäule mit Einengung des Spinalkanals. Bereits 1992 konnten Nau et al. in einer Studie durch intrathekale Injektion von Indium-Diethylentriaminpentaessigsäure (In-DTPA) zeigen, dass eine pathologische Erhöhung des Gesamtproteins im Liquor


Schranke im Zuge einer entzündlichen ZNS-Erkrankung zurückzuführen ist. Vielmehr stelle der verminderte Liquorfluss eine wichtige Teilursache für einen Anstieg des Gesamtproteins und des $Q_{\text {Albumin }}$ dar (Nau et al. 1992). In unserem geriatrischmultimorbiden Patientenkollektiv beobachteten wir ein erhöhtes $Q_{\text {Albumin }}$ im Vergleich zur Reiber-Formel (4+Alter/15) $\times 10^{-3}$ bei $18,7 \%$ der Patienten ohne Entzündungszeichen im Liquor. Dies steht in Übereinstimmung mit anderen Studien (Brettschneider et al. 2005). Bei allen Patienten mit einem deutlich erhöhten $Q_{\text {Albumin }}$ soll eine metabolische oder zerebrovaskuläre Genese ausgeschlossen werden, ebenso wie eine Spinalkanalstenose (Brettschneider et al. 2005). 
Einhergehend mit der o.g. Untersuchung des Liquor/Serum-Albumin-Verhältnisses beurteilten wir ebenso die Serumalbuminkonzentration unserer Patienten. Hier stellte sich heraus, dass die Serumalbuminkonzentration bei unseren Patienten älter als 65 Jahre erniedrigt war. Auch in anderen Studien konnte gezeigt werden, dass mit steigendem Alter die Albuminkonzentration im Serum abnimmt und diese sogar mit einem erhöhten Risiko für die Entwicklung einer Herzinsuffizienz verbunden ist (Gopal et al. 2010).

Des Weiteren zeigten unsere Patienten über 65 Jahre eine signifikante Erhöhung der IgA-Serumkonzentration. Auch hier lässt sich unser Ergebnis der erhöhten IgASerumkonzentrationen im Alter mit anderen Studien in Übereinstimmung bringen (Weber-Mzell et al. 2004). Die Ursache für diese erhöhte lgA-Serumkonzentration liegt vermutlich an einer vermehrten polyklonalen B-Zell-Aktivierung im Alter (De Greef et al. 1992).

Eine weitere Fragestellung unserer Studie nimmt Bezug auf eine quantitative Auswertung von Komplikationen nach einer Lumbalpunktion. Hier wurde als einzige Komplikation der postpunktionelle Kopfschmerz nur bei einem unserer geriatrischen Patienten und einem Patienten jünger als 65 Jahre dokumentiert. Dies lässt vermuten, dass nur in sehr seltenen Fällen ein postpunktioneller Kopfschmerz (PPKS) auftritt, auch wenn die Untererfassung solcher Fälle in einer retrospektiven Studie mit bedacht werden muss. Weitere unerwünschte Ereignisse wurden nicht beobachtet.

Eine Verbesserung des Gangbildes und der neuropsychologischen Funktionen wurde bei $37 \%$ der geriatrischen Patienten mit Verdacht auf NPH nach einer Lumbalpunktion mit Liquorablassversuch registriert. Das zeigt die sehr wichtige Rolle der Lumbalpunktion als eine "nicht-maximalinvasive“ Methode zur Diagnose eines Normaldruckhydrozephalus, obwohl die Sensitivität der Lumbalpunktion für diese Indikation als gering angesehen wird (26-61\%). Eine höhere Sensitivität (50-100\%), gepaart mit einem positiv-prädiktiven Wert von ca. 80-100\%, liefert die Methode der externen Ventrikeldrainage mit einem maximalen Liquorablass von $300 \mathrm{ml}$ über 72 Stunden (Marmarou 2005, Shprecher et al. 2008). Da die Diagnosestellung eines 
$\mathrm{NPH}$ zuweilen nicht ganz eindeutig getroffen werden kann und so die operative Versorgung mittels ventrikulo-peritonealen Shunt (VPS) bei einem Teil der Patienten nicht indiziert ist, bei einem anderen aber fälschlich unterlassen wird, müssen sensitivere Methoden und Tests zur Diagnosesicherung des NPH entwickelt werden (Shprecher et al. 2008).

In der Literatur findet man einige Arbeiten, die sich mit dieser Problematik auseinandersetzen. In einer Studie wurden verschiedene Parameter (Ganggeschwindigkeit, Schrittlänge und Schrittrhythmus) vor und nach einer high-volume-lumbarpuncture (hVLP), Liquorablass $>30 \mathrm{ml}$, bestimmt und verglichen. Nach einer signifikanten Besserung dieser Werte bei Patienten nach hVLP mit NPH, könnten diese Parameter einen prognostischen Wert für die Anlage eines VPS haben (Mary et al. 2013). Eine andere Studie konnte zeigen, dass 48 von 61 Patienten mit NPH von einem VPS profitierten. Diese Patienten hatten eine signifikant längere Körpergröße (Mittelwert $165 \mathrm{~cm}$ ) als die Patientengruppe ohne Verbesserung (Mittelwert $152 \mathrm{~cm}$ ) durch VPS-Anlage. Aus dieser Studie lässt sich die Körperlänge eines Patienten als prognostischer Wert für die Anlage eines VPS erschließen (Aguas et al. 2013). Diese beiden Studien unterstreichen die Schwierigkeiten und den hohen Stellenwert einer sicheren Diagnosestellung des NPH, da der gesicherte NPH durch Anlage eines ventrikulo-peritonealen Shunts therapiert werden kann und sollte. Noch vor ca. 20 Jahren galt diese operative Versorgung des NPH mittels ventrikulo-peritonealen Shunts als problematisch, da bei 35-40\% der Patienten die Anlage des Shunts mit Komplikationen wie u.a. Infektionen, subdurale Hämatome und Über/Unterdrainierung einherging (Drake et al. 1995). Heutzutage konnte diese Komplikationsrate u.a. durch neue Methoden und bessere Ventildesigns um über die Hälfte $(<20 \%)$ reduziert werden (Kiefer und Unterberg 2012). Auch liefert die Behandlung des NPH mit Hilfe eines VPS die besten Langzeitergebnisse in Bezug auf die Symptombesserung (Gangunsicherheit, Urininkontinenz und Demenz), 70$90 \%$ der Patienten mit VPS profitieren langfristig (Kiefer und Unterberg 2012).

Auch können wiederholte Lumbalpunktionen als therapeutische Option sehr wichtig für multimorbide Patienten mit einem erhöhten Operations-Risiko sein, aber auch als Alternative zur Anlage eines VPS angesehen werden, falls ein individuelles OPRisiko als zu hoch eingestuft wird (Lim et al. 2009). Dennoch stellt heutzutage die 
Shunt-Operation die Methode der ersten Wahl zur Behandlung des NPH dar (Kiefer und Unterberg 2012).

\section{Zusammenfassung}

Aufgrund der demographischen Entwicklung, der sich bessernden medizinischen Versorgung, der Fortschritte durch neue Medikamente und Behandlungsmethoden, neuer Kenntnisse im Bereich der Intensivmedizin und vieler weiterer Innovationen rückt die Behandlung von multimorbid-geriatrischen Patienten immer mehr in den Fokus der modernen Medizin. Lag die durchschnittliche Lebenserwartung neugeborener Jungen 1985/87 noch bei 71,54 Jahren und neugeborener Mädchen bei 78,37 Jahren, so stieg sie bis auf 77,72 Jahre für Jungen und 82,73 Jahre für Mädchen in dem Berechnungszeitraum 2009/2011 an. Bis zum Jahr 2060 werden Schätzungen zufolge ca. $34 \%$ der deutschen Bevölkerung über 65 Jahre alt sein. Dieser demographische Wandel bedeutet für die zukünftige und auch schon für die heutige Medizin, dass die Behandlung von geriatrischen Patienten eine zentrale Aufgabe der medizinischen Versorgung sein wird.

Eine wichtige Rolle in Bezug auf multimorbid-geriatrische Patienten ist das Wissen um die (Patho-)Physiologie der älteren Menschen, besonders die Wechselwirkungen der verschiedenen Krankheiten untereinander. Ältere Menschen besitzen wie Kinder einen anderen Metabolismus und sollten daher nicht als „alte Erwachsene“ gesehen werden (in der Pädiatrie gilt der Patient auch nicht als „kleiner Erwachsener“).

Aus diesem Grund ist es unausweichlich, den geriatrischen Patienten mehr in den Fokus von aktuellen Studien zu stellen. Therapeutische und diagnostische Methoden müssen an den geriatrischen Patienten angepasst werden. Sie müssen effektiv, möglichst minimalinvasiv und kostengünstig sein. Auch die Beurteilung von vermeintlich pathologischen Laborparametern, wie etwa die Liquorroutineparameter, muss überdacht werden. 
Vorliegende retrospektive Studie nimmt Bezug auf diese Problematik.

Anhand eines Kollektivs von 203 Patienten mit einem Durchschnittsalter von 72,5 \pm 16,4 Jahren, die sich in einem Zeitraum von 4 Jahren am Evangelischen Krankenhaus Weende-Göttingen einer Lumbalpunktion unterzogen hatten, konnte gezeigt werden, dass es altersabhängige Liquorroutineparameter $\left(Q_{\text {Albumin }}\right.$ und Liquorlaktatkonzentration) gibt. Es zeigten sich sowohl signifikante Erhöhungen der Liquorlaktatkonzentration als auch des $Q_{\text {Albumin }}$ bei Patienten älter als 65 Jahre ohne gleichzeitige Entzündung des ZNS gegenüber Patienten jünger als 65 Jahre. Ebenso korrelierte bei Abwesenheit von Entzündungszeichen die Liquorlaktatkonzentration signifikant mit dem Alter der Patienten. Dieses Ergebnis kann so gedeutet werden, dass beide Parameter sehr häufig bei älteren Patienten ohne spezifische therapeutische Konsequenz erhöht sind.

Des Weiteren wurde gezeigt, dass die Lumbalpunktion eine wichtige Rolle als diagnostisches und therapeutisches Werkzeug für geriatrische Patienten einnimmt, sei es u.a. zur Bestätigung oder zum Ausschluss einer ZNS-Infektion, einer entzündlichen Autoimmunerkrankung, einer Demenz oder zur Behandlung bzw. Diagnostik eines NPH.

Nur in einem von 110 Verdachtsfällen konnte eine bakterielle und nur in 9 Fällen eine virale Meningitis durch eine Lumbalpunktion gesichert werden. Bei zwei Patienten zeigte sich eine HSV-Enzephalitis. Beide dieser Patienten waren unter 65 Jahre. Im Ganzen entspricht dies einer Verdachtsdiagnosenbestätigung durch eine Lumbalpunktion von ca. $9 \%$. Außerdem konnte ein entzündliches Geschehen im ZNS durch Liquoranalyse bei 1,8\% älter als 65 Jahre und bei 2,8\% jünger als 65 Jahre festgestellt werden, ohne dass zuvor ein klinischer Verdacht auf Entzündung des ZNS vor der Lumbalpunktion bestanden hatte. Bei 17 Patienten mit Verdacht auf Demenz und der gleichzeitigen Bestimmung der Demenzmarker konnten in 14 Fällen pathologische Werte ermittelt werden, dies entspricht einer Korrelation von ca. $85 \%$.

Bei 2 von 34 Patienten jünger als 65 Jahre und bei 9 von 105 Patienten älter als 65 Jahre ergab die Auswertung des Liquors oligoklonale IgG-Banden. Bei Patienten über 65 Jahre konnte die intrathekale IgG-Synthese in Zusammenhang mit einer ZNS-Infektion gebracht werden, bei Patienten jünger als 65 Jahre spricht dies eher für eine chronisch-entzündliche Erkrankung. 
Des Weiteren konnte bei 10 von 27 Patienten mit Verdacht auf NPH nach Liquorablass eine klinische Verbesserung der Symptomatik beobachtet werden. 2 von diesen Patienten erhielten einen ventrikulo-peritonealen Shunt.

Die Lumbalpunktion ist ein minimalinvasives Verfahren, komplikationsarm, finanziell tragbar und sehr effektiv, um insbesondere ZNS-Infektionen bei kognitiv beeinträchtigten Patienten auszuschließen. Aus diesem Grund sollte die Lumbalpunktion und die schnelle Analyse von Liquorroutineparametern in jeder geriatrischen Abteilung durchgeführt werden.

Weitere Studien und Untersuchungen an geriatrischen Patienten werden vonnöten sein, um in Zukunft effektive Behandlungen und Rehabilitationen zu gewährleisten. 


\section{$6 \quad$ Literaturverzeichnis}

1. Aguas J, Rodrigo V, Estupiñan F, Nogues P, Villalba G, Villagrasa J, Caral L (2013): Normal pressure hydrocephalus: Prognostic value of height in patients treated with an identical shunt system. Neurocirugia (Astur) $\underline{24}, 102-109$

2. Armon C, Evans RW (2005): Addendum to assessment: Prevention of post-lumbar puncture headaches: report of the Therapeutics and Technology Assessment Subcommittee of the American Academy of Neurology. Neurology $\underline{65}, 510-512$

3. Biesiada G, Czepiel J, Sobczyk-Krupiarz I, Mach T, Garlicki A (2010): Neurological complications among patients with zoster hospitalized in Department of Infectious Diseases in Cracow in 2001-2006. Przegl Lek $\underline{67}$, 149-150

4. Blennow K, Fredman P, Wallin A, Gottfries CG, Karlsson I, Långström G, Skoog I, Svennerholm L, Wikkelsö C (1993): Protein analysis in cerebrospinal fluid. II. Reference values derived from healthy individuals $18-88$ years of age. Eur Neurol $\underline{33}$, 129-133

5. Brettschneider J, Claus A, Kassubek J, Tumani H (2005): Isolated bloodcerebrospinal fluid barrier dysfunction: prevalence and associated diseases. J Neurol 252, 1067-1073

6. Brouns R, Sheorajpanday R, Wauters A, De Surgeloose D, Mariën P, De Deyn PP (2008): Evaluation of lactate as a marker of metabolic stress and cause of secondary damage in acute ischemic stroke or TIA. Clin Chim Acta 397, 27-31

7. Carson D, Serpell M (1996): Choosing the best needle for diagnostic lumbar puncture. Neurology 4 77 (1), 33-37

8. Castells A, Parvas M, Bueno D. (2012): Homeostasis of cerebrospinal fluid has a role in early brain development. Neuroreport. Nov 14; 23 (16), 917-921

9. Conly JM, Ronald AR (1983): Cerebrospinal fluid as a diagnostic body fluid. Am J Med $\underline{75}, 102-107$

10. Corning JL (1885): Spinal anaesthesia and local medication of the cord. NY State Med J $\underline{42}, 483$ 
11. Cunha BA, Strollo S, Durie N, Ibrahim MS (2011): Facial herpes zoster complicated by varicella zoster virus (VZV) encephalitis: The diagnostic significance of atypical lymphocytes in cerebrospinal fluid (CSF). Heart Lung 40, 164-167

12. Dakka Y, Warra N, Albadareen RJ, Jankowski M, Silver B (2011): Headache rate and cost of care following lumbar puncture at a single tertiary care hospital. Neurology $\underline{77}, 71-74$

13. Daube JR, Frishberg BM, Greenberg MK (1993): Report of the Quality Standards Subcommittee of the American Academy of Neurology. Practice parameters: lumbar puncture. Neurology $\underline{43}, 625-627$

14. Davson H, Segal MB (eds): Physiology of the CSF and blood-brain barriers. CRC Press, Boca Raton 1996

15. De Greef GE, Tol MJ van, Berg JW van den et al. (1992). Serum immunoglobulin class and IgG subclass levels and the occurrence of homogeneous immunoglobulins during the course of ageing in humans. Mech Ageing Dev $\underline{66}, 29-44$

16. Diener H-C, Weimer Ch (eds.): Leitlinien für Diagnostik und Therapie in der Neurologie. Herausgegeben von der Kommission "Leitlinien“ der Deutschen Gesellschaft für Neurologie. Georg Thieme Verlag, Stuttgart 2012

17. Djukic M, Schmidt-Samoa $C$, Lange $P$, Spreer A, Neubieser K, Eiffert $H$, Nau R, Schmidt H. (2012): Cerebrospinal fluid findings in adults with acute Lyme neuroborreliosis. J Neurol 259 (4), 630-636

17. Drake JM, Sainte-Rose C (eds): The Shunt Book. Blackwell Science Inc., Oxford 1995

19. Encyclopaedia Britannica:

www.britannica.com/EBchecked/topic/356563/Francois-Magendie

20. Evans RW (1998): Complications of lumbar puncture. Neurol Clin 16, 83-105

21. Evans RW, Armon C, Frohman EM, Goodin DS (2000): Assessment: Prevention of post-lumbar puncture headaches: report of the Therapeutics and Technology Assessment Subcommittee of the American Academy of Neurology. Neurology Oct $10, \underline{55(7)}, 909-91$

22. Finsterer J (2001): Cerebrospinal-fluid lactate in adult mitochondriopathy with and without encephalopathy. Acta Med Austriaca $\underline{28}, 152-155$ 
23. Flaatten H, Kråkenes J, Vedeler C (1998): Post-dural puncture related complications after diagnostic lumbar puncture, myelography and spinal anaesthesia. Acta Neurol Scand $\underline{98}, 445-451$

24. Garcia T, Killian JA, De Sanctis A (1928): The lactic acid and the sugar content of the spinal fluid in meningitis. Arch Pathol $\underline{6}, 530$

25. Gopal DM, Kalogeropoulos AP, Georgiopoulou VV, Tang WW, Methvin A, Smith AL, Bauer DC, Newman AB, Kim L, Harris TB et al. (2010): Serum albumin concentration and heart failure risk. The Health, Aging, and Body Composition Study. Am Heart J 160, 279-285

26. Gröschel K, Schnaudigel S, Pilgram S.M, Wasser K, Kastrup A (2008): Die diagnostische Lumbalpunktion. Dtsch Med Wochenschr $\underline{133}$, 39-41

27. Hindley NJ, Jobst KA, King E, Barnetson L, Smith A, Haigh AM (1995): High acceptability and low morbidity of diagnostic lumbar puncture in elderly subjects of mixed cognitive status. Acta Neurol Scand $\underline{91}, 405-411$

28. Hoffmann JJ, Janssen WC (2002): Automated counting of cells in cerebrospinal fluid using the CellDyn-4000 maematology analyser. Clin Chem Lab Med 40 (11), 1168-1173

29. Hornig CR, Busse O, Kaps M (1983): Importance of cerebrospinal fluid lactate determination in neurological diseases. Klin Wochenschr $\underline{61}$, 357-361

30. Huffner H, Henninger N, Dieler S: Erhöhter intrakranieller Druck; in: Schwab S, Schellinger P, Werner C, Unterberg A, Hacke W (eds.): Neurolntensiv. Springer Verlag, Berlin, Heidelberg, New York 2012

31. Iqbal J, Davis LE, Orrison WW, Jr (1995): An MRI study of lumbar puncture headaches. Headaches 35 (7), 420-422

32. Jesse $S$, Brettschneider J, Süssmuth $S D$, Landwehrmeyer BG, von Arnim $C A$, Ludolph AC, Tumani H, Otto M (2011): Summary of cerebrospinal fluid routine parameters in neurodegenerative diseases. J Neurol $\underline{258}, 1034-1041$

33. Kiefer M, Unterberg A (2012): The Differential Diagnosis and Treatment of Normal-Pressure Hydrocephalus. Dtsch Arztebl Int 109, 15-26

34. Killian JA (1925): Sugar and lactic acid of spinal fluid in meningitis. Proc Soc Exper Biol Med $\underline{23}, 255$ 
35. Kleine TO: Lactat; in: Zettl UK, Lehmitz R, Mix E (eds): Klinische Liquordiagnostik. Walter de Gruyter; Berlin 2003, 130-133

36. Kleine TO, Baehrlocher K, Niederer V, Keller H, Teuter F, Tritschler W, Bablock W. (1979): Die diagnostische Bedeutung der Lactatbestimmung im Liquor bei Meningitis. Dtsch Med Wschr 104, 553-557

37. Lehmnitz R, Hobusch D, Kluge H, Mix E, Zettl UK: Referenzwerte für Liquorparameter mit diagnostischer Relevanz; in: Zettl U, Lehmnitz R, Mix E, Klinische Liquordiagnostik, $2^{\text {nd }}$ edn. Walter de Gruyter, Berlin 2005, 88-94

38. Lim TS, Yong SW, Moon SY (2009): Repetitive lumbar punctures as treatment for normal pressure hydrocephalus. Eur Neurol $\underline{62}, 293-297$

39. Luft D, Götz R (1983): Lactat im Liquor cerebrospinalis. Bedeutung für Differentialdiagnose, Therapiekontrolle und Prognose zerebraler und meningealer Erkrankungen. Lab Med $\underline{7}, 55-59$

40. Marmarou A, Bergsneider M, Klinge P, Relkin N, Black PM (2005): The value of supplemental prognostic tests for the preoperative assessment of idiopathic normalpressure hydrocephalus. Neurosurgery $\underline{57}, 17-28$

41. Mary P, Gallisa JM, Laroque S, Bedou G, Maillard A, Bousquet C, Negre C, Gaillard N, Dutray A, Fadat B et al. (2013): Predictive value of postural and dynamic walking parameters after high-volume lumbar puncture in normal pressure hydrocephalus. Rev Neurol (Paris) 169, 321-327

42. Masuhr K, Neumann M (eds): Neurologie. 6. Auflage, Duale Reihe, Georg Thieme Verlag, Stuttgart 2007, 104-114; 123-127

43. May C, Kaye JA, Atack JR, Schapiro MD, Friedland RP, Raport SI (1990): Cerebrospinal fluid production is reduced in healthy aging. Neurology $\underline{40}, 500-503$

44. Nagel MA, Cohrs RJ, Mahalingam R, Wellish MC, Forghani B, Schiller A, Safdieh JE, Kamenkovich E, Ostrow LW, Levy M et al. (2008): The varicella zoster virus vasculopathies: clinical, CSF, imaging, and virologic features. Neurology $\underline{70}, 853-860$ 45. Nau R, Emrich D, Prange HW (1992): Inverse correlation between disappearance of intrathecally injected ${ }^{111}$ In-DTPA from CSF with CSF protein conten and CSF-toserum albumin ratio. J Neurol Sci $\underline{115}, 102-104$ 
46. Nau R, Lantsch M, Stiefel M, Polak T, Reiber H (1998): Varicella zoster virus.associated focal vasculitis without herpes zoster: recovery after treatment with acyclovir. Neurology $\underline{51}, 914-915$

47. Oschmann P, Kunesch E, Zettl UK: Liquorpunktion-Indikationen, Techniken und Komplikationen; in: Zettl U, Lehmitz R, Mix E (eds.): Klinische Liquordiagnostik. 2. Auflage; de Gruyter, Berlin 2005

48. Parnetti L, Gaiti A, Polidori MC, Brunetti M, Palumbo B, Chionne F, Cadini D, Cecchetti R, Senin U (1995): Increased cerebrospinal fluid pyruvate levels in Alzheimer's disease. Neurosci Lett $\underline{199}, 231-233$

49. Petereit H-F, Sindern E, Wick M (eds): Leitlinien der Liquordiagnostik und Methodenkatalog der Deutschen Gesellschaft für Liquordiagnostik und Klinische Neurochemie. Springer Medizin Verlag, Heidelberg 2007

50. Prange J: D- und L-Laktat bei bakterieller Meningitis. Med. Diss. Göttingen 2004

51. Posner JB, Plum F (1967): Independence of blood and CSF lactate. Arch Neurol $\underline{16}, 494-496$

52. Quincke H (1891): Über Hydrocephalus. Verhandl Cong Inn Med 10, 321

53. Ratzka P, Schlachetzki JC, Bähr M, Nau R (2006): Varicella zoster virus cerebellitis in a 66-year-old patient without herpes zoster. Lancet $\underline{367}, 182$

54. Reiber H (1980): Eine schnelle und einfache nephelometrische Bestimmungsmethode für Protein im Liquor cerebrospinalis. J Clin Chem Clin Biochem 1980a, 18, 1237

55. Reiber H (2003): Proteins in cerebrospinal fluid and blood: Barriers, CSF flow rate and source-related dyanmics. Restor Neurol Neurosci 21, 79-96

56. $($ Reiber 2006a) $=$ Reiber $\mathrm{H}$ : Liquorräume, Liquorbildung und Liquorfluss; in: Wildemann B, Oschmann P, Reiber H (eds): Neurologische Labordiagnostik. Georg Thieme Verlag, Stuttgart 2006, 3-4

57. (Reiber 2006b) = Reiber H: Methodische Grundlagen der Analytik; in: Wildemann B, Oschmann P, Reiber H (eds): Neurologische Labordiagnostik. Georg Thieme Verlag, Stuttgart 2006, 17-29 
58. $($ Reiber 2006c) = Reiber $\mathrm{H}$ : Lactat, Glucose; in: Wildemann $\mathrm{B}$, Oschmann $\mathrm{P}$, Reiber H. (eds): Neurologische Labordiagnostik. Georg Thieme Verlag, Stuttgart 2006, 55-58

59. Reiber H, Felgenhauer K (1987): Protein transfer at the blood cerebrospinal fluid barrier and the quantitation of the humoral immune response within the central nervous system. Clin Chim Acta 163, 319-328

60. Reiber H, Lange P (1991): Quantification of virus-specific antibodies in cerebrospinal fluid and serum: sensitive and specific detection of antibody synthesis in brain. Clin Chem $\underline{37}, 1153-1160$

61. Reiber H, Otto M, Trendelenburg C, Wormek A (2001): Reporting cerebrospinal fluid data: knowledge base and interpretation software. Clin Chem Lab Med 39, 324332

62. Rotbart HA (2000): Viral meningitis. Semin Neurol $\underline{3}, 277-292$

63. Sakka L, Coll G, Chazal J (2011): Anatomy and physiology of cerebrospinal fluid. Eur Ann Otorhinolaryngol Head Neck Dis $\underline{128}, 309-316$

64. Shprecher D, Schwalb J, Kurlan R (2008): Normal Pressure Hydrocephalus: Diagnosis and Treatment. Curr Neurol Neurosci Rep $\underline{8}, 371-376$.

65. Staib F, Seibold M, Antweiler E, Zimmer C, Heitz J, Stoltenburg-Didinger G (1990): Cerebrospinal fluid indices in cryptococcal and tuberculous meningitis: the spider web coagulum and its diagnostic significance. Mycoses Jul-Aug, 33 (7-8), 359367

66. Statistisches Bundesamt: Krankenhausdiagnostik- Diagnosedaten der Patienten und Patientinnen in Krankenhäusern. www.gbe-bund.de. Last accessed 12. April 2011

67. (Storch-Hagenlocher 2006a) = Storch-Hagenlocher B: Liquorpunktion; in: Wildemann B, Oschmann P, Reiber H (eds): Neurologische Labordiagnostik. Georg Thieme Verlag, Stuttgart 2006, 30-34

68. (Storch-Hagenlocher 2006b) = Storch-Hagenlocher B: Zelldiagnostik; in: Wildemann B, Oschmann P, Reiber H (eds): Neurologische Labordiagnostik. Georg Thieme Verlag, Stuttgart 2006, 35-45 
69. Strupp M, Schueler O, Straube A, Von Stuckrad-Barre S, Brandt T (2001): "Atraumatic" Sprotte needle reduces the incidence of post-lumbar puncture headaches. Neurology $\underline{57}, 2310-2312$

70. Tavazzi E, Minoli L, Ferrante P, Scagnelli P, Del Bue S, Romani A, Ravaglia S, Marchioni E (2008): Varicella zoster virus meningo-encephalo-myelitis in an immunocompetent patient. Neurol Sci $\underline{29}$, 279-283

71. Thiel E, Gleissner B (2006): Meningeosis neoplastica. Dtsch Ärztebl $\underline{39}$ (Jg. 103), A $2995-65$

72. Veening JG, Barendregt HP (2010): The regulation of brain states by neuroactive substances distributed via the cerebrospinal fluid; a review. Cerebrospinal Fluid Res $\underline{7}, 1$

73. Walz W, Mukerji S (1988): Lactate release from cultured astrocytes and neurons: A comparison. Glia 1 , 366-370

74. Wang LP, Schmidt JF (1997): Central nervous side effects after lumbal puncture. A review of the possible pathogenesis of the syndrome of postdural puncture headache and associated symptoms. Dan Med Bull 47 (1), 79-81

75. Weber-Mzell D, Kotanko P, Hauer AC, Goriup U, Haas J, Lanner N, Erwa W, Ahmaida IA, Haitchi-Petnehazy S, Stenzel M et al (2004): Gender, age and seasonal effects on IgA deficiency: a study of 7293 Caucasians. Eur J Clin Invest. $\underline{34}$, 224-228

76. Wellmer A, Prange J, Gerber J, Zysk G, Lange P, Michel U, Eiffert H, Nau R (2001): D- and L-lactate in rabbit and human bacterial meningitis. Scand. J Infect Dis $\underline{33}(12), 909-913$

77. Wurster U: Elektrophorese Verfahren - Nachweis und Bedeutung von oligoklonalen Banden; in: Zettl UK, Lehmitz R, Mix E (eds): Klinische Labordiagnostik. 1. Auflage; de Gruyter, Berlin 2003, 207-236

78. Zettl U, Lehmitz R, Mix E (Hrsg.): Klinische Liquordiagnostik. 2. Auflage; de Gruyter, Berlin 2005 


\section{Lebenslauf}

Am 28. August 1985 wurde ich als drittes Kind der Eheleute Sabine Franke-Schulz, geborene Franke, und Martin Schulz in Bremerhaven geboren. Meine Mutter arbeitet als Direktorin einer Oberschule in Dorum und mein Vater ist Mathematiker und Hausmann. Anka Mitgau, geborene Schulz, und Philipp Schulz sind meine älteren Geschwister und arbeiten als Oberstudienrätin bzw. Zahnarzt.

Von 1992 bis 1996 besuchte ich die Grundschule in Dorum, danach von 1996 bis 1998 die Orientierungsstufe der Bleickenschule in Cuxhaven. Anschließend wechselte ich auf das Amandus-Abendroth-Gymnasium in Cuxhaven, an dem ich im Juni 2005 die Allgemeine Hochschulreife erlangte.

Während meiner Schulzeit nahm ich 1998 an dem Wettbewerb Jugend forscht teil und erhielt den 1. Platz in der Kategorie Mathematik mit dem Thema „Alea iacta est“. Des Weiteren erhielt ich im Juni 2004 die Auszeichnung der GGH (Gustav G. Herold) -Stiftung für die beste Facharbeit im Bereich Mathematik mit dem Thema „Einführung in die Komplexen Zahlen“. Im Juni 2005 wurde mir der DPG (Deutsche Physikalische Gesellschaft) -Buchpreis als Anerkennung für „herausragende Leistungen“ im Fach Physik verliehen.

Nach meiner Schulzeit leistete ich bis Juli 2006 meinen Zivildienst im Bereich der ambulanten Krankenpflege in der DRK-Sozialstation Midlum ab. Zum Wintersemester 2006 immatrikulierte ich mich an der Georg-August-Universität Göttingen für die Fächer Mathematik und Sport auf Lehramt SEK II. Nach Abbruch des Studiums im darauffolgenden Jahr begann ich im Mai 2007 mein 3-monatiges Krankenpflegepraktikum an der Seepark Klinik Debstedt in der Abteilung Urologie und Kinderurologie. Von 2007 bis 2008 war ich an der FH Oldenburg-OstfrieslandWilhelmshaven für das Fach Nautik immatrikuliert und absolvierte von Januar bis April 2008 mein Praxissemester an Bord der „MS Paranagua Express“. Ab April 2008 leistete ich bis zum September 2008 ein unentgeltliches Praktikum an der Seepark Klinik Debstedt in der Abteilung Urologie und Kinderurologie ab. Zum Wintersemester 2008 immatrikulierte ich mich erneut an der Georg-August- 
Universität Göttingen für das Fach Humanmedizin. Im September 2010 legte ich den Ersten Abschnitt der Ärztlichen Prüfung mit der Note gut ab.

Von Mai 2011 bis Juli 2012 arbeitete ich als Aushilfskraft in der Abteilung Klinische Neurophysiologie der Universitätsmedizin Göttingen. Des Weiteren arbeite ich seit September 2011 als studentische Aushilfe im Bereich Pflege im Evangelischen Krankenhaus Weende.

Seit August 2013 befinde ich mich im Praktischen Jahr (Innere Medizin, Chirurgie und Urologie) am Klinikum der Georg-August-Universität in Göttingen und am Evangelischen Krankenhaus Weende. Dieses werde ich voraussichtlich im Juli 2014 beenden und meinen Zweiten Abschnitt der Ärztlichen Prüfung absolvieren. 